\title{
Recursos orgánicos y objetos arqueológicos en la localidad Cerro La China: ilaciones a partir de las sustancias grasas
}

\author{
Natalia Mazzia \\ (iD) https://orcid.org/0000-0002-7708-0374 \\ Área Arqueología y Antropología, Área de Museos, Municipalidad de Necochea - Consejo Nacional de \\ Investigaciones Científicas y Técnicas (CONICET). Av. 10 y calle 63 (CP B7630), Necochea, Buenos Aires, \\ Argentina. E-mail: natymazzia@yahoo.com.ar
}

Nora Flegenheimer

Área Arqueología y Antropología, Área de Museos, Municipalidad de Necochea - Consejo Nacional de Investigaciones Científicas y Técnicas (CONICET). Av. 10 y calle 63 (CP B7630), Necochea, Buenos Aires, Argentina. E-mail: norafleg@gmail.com

\begin{abstract}
Resumen
En este trabajo presentamos los resultados de los análisis desarrollados sobre un total de 46 objetos líticos, un fragmento cerámico y cinco muestras de sedimentos, correspondientes a los sitios de la localidad arqueológica Cerro La China (centro-este de Tandilia, Buenos Aires, Argentina) y sus diferentes momentos de ocupación. Los objetos líticos muestreados fueron manufacturados en diversas materias primas e incluyen una gran variedad de tipos de instrumentos. Los resultados dan cuenta de una importante preservación de las muestras y de la ausencia de contaminación por la matriz sedimentaria. Se destaca la identificación de recursos orgánicos de diferentes orígenes: aceites vegetales en general, aceite de semillas, posibilidad de enmangue con mástic vegetal, grasas de animales terrestres, mezcla de grasas de diferentes orígenes y grasas de animales acuáticos.
\end{abstract}

PALABRAS CLAVE: Análisis lítico; Uso de artefactos; Región pampeana.

\section{Organic resources and archaeological objects from Cerro La China locality: inferences based on fatty substances}

\begin{abstract}
In this paper, we present the results obtained from analyzing 46 lithic artifacts, one potsherd, and five sediment samples, all coming from sites at Cerro La China archaeological locality (center-east Tandilia, Buenos Aires, Argentina) and its different occupation moments. The sampled lithic objects were manufactured on various raw
\end{abstract}


materials, and they include a large variety of stone tools. Results exhibit remarkable preservation of the samples and lack of contamination due to contact with sediments. Several organic resources of different origins could be identified; these include vegetal oils in general, seed oils, possible vegetal mastic, land animal fats, a mixture of fats from different sources, and aquatic animal fats.

KEYWORDS: Lithic analysis; Artifact use; Pampean region.

\section{Introducción}

La localidad arqueológica Cerro La China está ubicada sobre la ladera sudeste de una serranía de apenas $227 \mathrm{~m}$ s.n.m. del sistema de Tandilia, al noreste del partido de Lobería, Buenos Aires (Figura 1). Allí se estudiaron tres sitios arqueológicos: un abrigo y dos a cielo abierto, estos últimos al reparo de los afloramientos del cerro. Si bien los mencionados sitios son conocidos principalmente por sus ocupaciones tempranas, con fechados de cerca de 11.000 años AP (Flegenheimer, Mazzia y Weitzel, 2015), también se han identificado ocupaciones correspondientes al Holoceno medio y tardío, incluyendo evidencias de momentos post-conquista (Mazzia y Flegenheimer, 2007).

Las interpretaciones sobre los diferentes momentos de ocupación fueron realizadas a partir de sus características espaciales y del análisis de los materiales líticos, predominantes en todos los conjuntos. Debido a la escasa preservación de macrorrestos animales y vegetales, es poca la información disponible sobre los recursos orgánicos utilizados en el pasado. Por ello, se desarrolló el análisis de sustancias grasas conservadas en las porosidades y microfracturas de los objetos mediante cromatografía de gases (Mazzia, 2013). Estos análisis resultan una vía para estudiar los recursos que estuvieron en contacto con los artefactos (p. ej. Baeten, Jervis, De Vos y Waelkens, 2013; Barba, Ortíz y Pecci, 2014; Evershed, 2008; Malainey, 2007; Pecci, Barba y Ortíz, 2017).

En tal sentido, en este trabajo buscamos obtener la mayor cantidad posible de información mediante análisis cromatográficos de sustancias grasas a partir de los artefactos en un contexto con escaso registro de macrorrestos orgánicos. La integración de estos resultados con las características tecnomorfológicas de los artefactos y la determinación de la procedencia de sus materias primas resulta un punto de partida para proponer relaciones que habrían establecido los grupos humanos a partir de sus movimientos cotidianos en el espacio pampeano.

\section{Sobre los sitios y las investigaciones}

La localidad arqueológica Cerro La China (LCH) se encuentra en las estribaciones australes de Sierra Larga (sector centro-oriental de Tandilia). Los tres sitios fueron objeto de un intenso estudio geoarqueológico que contribuyó a la organización cronológica de los materiales. A esto deben sumarse diez fechados radiocarbónicos y un fechado por TL que brindaron fechas absolutas a una secuencia de ocupaciones humanas que comienza durante el Pleistoceno final y llega hasta momentos posteriores a la conquista (Flegenheimer, 2004; Mazzia y Flegenheimer, 2007). En LCH se definieron cinco unidades estratigráficas, siendo arqueológicamente fértiles las tres superiores (Zárate, 1986-1987; Zárate y Flegenheimer, 1991). La Unidad 3, conformada por un depósito eólico, contiene materiales asignados a las primeras ocupaciones, incluyendo puntas de proyectil del tipo cola de pescado (PCP) y fechados de más de 10.000 años 

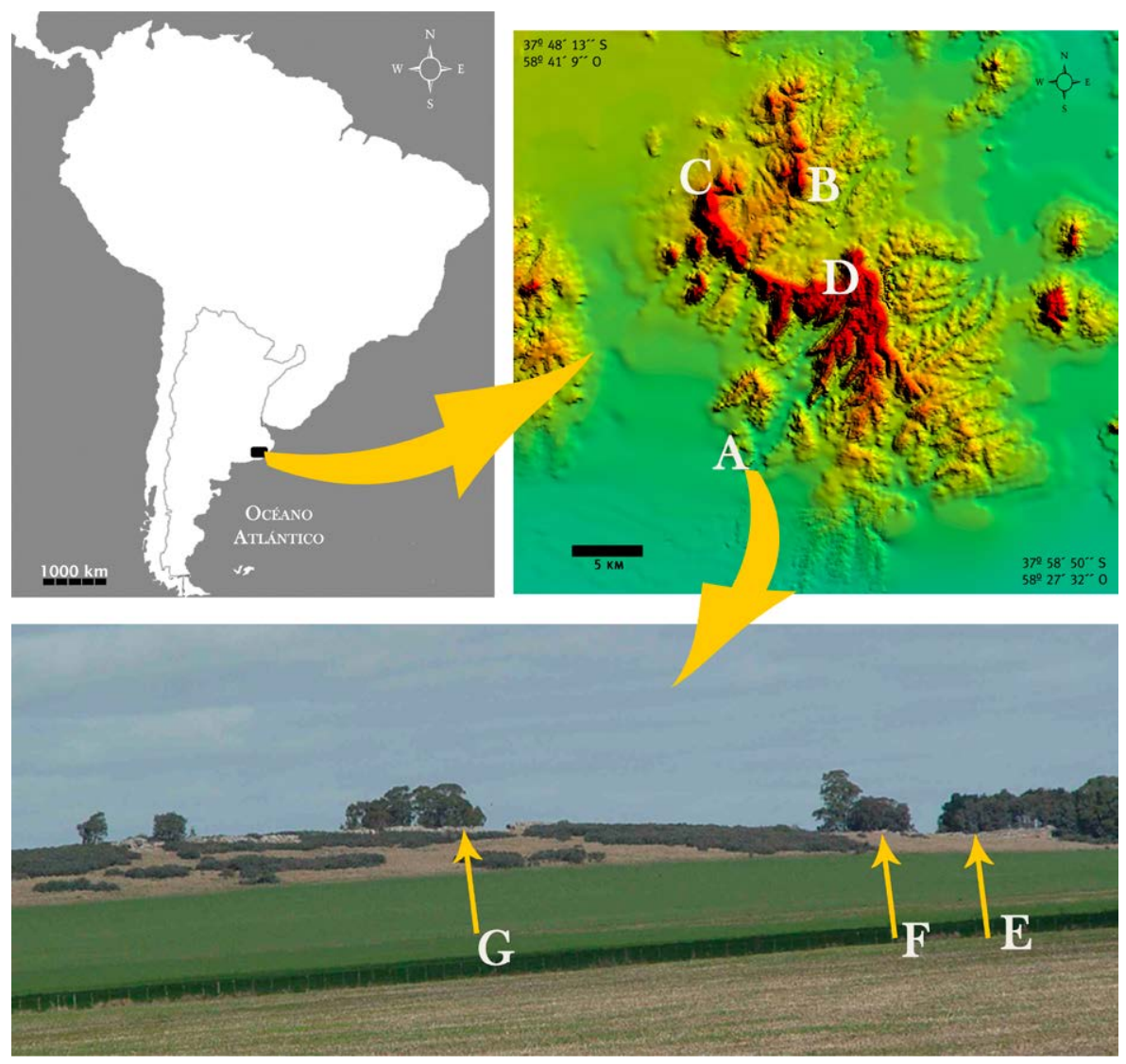

Figura 1. Localización de la localidad arqueológica Cerro La China (Tandilia, provincia de Buenos Aires). Referencias: A) Cerro La China; B) Cerro El Sombrero; C) Cueva Zoro; D) El Ajarafe; E) sitio 1 (LCH1); F) sitio 2 (LCH2); G) sitio 3 (LCH3).

de antigüedad (Flegenheimer, 2004; Zárate, 2005). Las Unidades 4 y 5 contienen los hallazgos de las ocupaciones más tardías. La Unidad 4 está formada por un depósito eólico del Holoceno medio-tardío afectado por un desarrollo de suelo incipiente (con horizontes $\mathrm{AC}$ o A/AC). En tanto, la Unidad 5 es un pequeño episodio de redepositación eólica sólo visible en algunos sectores (Zárate y Flegenheimer, 1991). Estas cinco unidades tienen distintas manifestaciones en los tres sitios: el perfil del sitio 3 es el más profundo, mientras que en el sitio 1 , con una estratigrafía más comprimida, las dos unidades superiores no se distinguen.

También se realizaron análisis espaciales integrando el uso de Sistemas de Información Geográfica con el registro de experiencias subjetivas sobre el terreno, evaluando condiciones generales de visibilidad, intervisibilidad, accesibilidad y recorridos posibles (Mazzia, 2010-2011). Los afloramientos que conforman la ladera sudeste de este cerro, con pendientes suaves, ofrecen numerosos espacios reparados entre los que es posible una buena comunicación. Además de la accesibilidad, el reparo y las buenas condiciones generales de visibilidad, hay numerosos manantiales entre los afloramientos de la ladera. Estas características convierten a esta pequeña serranía en un espacio interesante para habitar y desarrollar diferentes tareas, tal como lo demuestra la recurrencia de ocupación de los sitios a lo largo del Holoceno y la importante variabilidad intersitio registrada (Flegenheimer, 2004; Mazzia y Flegenheimer, 2007).

Particularmente sobre los objetos líticos, se realizaron análisis tecno-tipológicos, de distribución y de procedencia de las materias primas (Flegenheimer, 2004). Con 
mayor detalle fueron estudiados los instrumentos asignados a las ocupaciones más tempranas; en ellos se abordó el estudio de las fracturas (Weitzel y Flegenheimer, 2011) y, sobre una muestra, un análisis funcional de base microscópica (Leipus, 2002).

En adelante se sintetizan los cambios y las continuidades en la forma e intensidad con la que fueron habitados $\mathrm{y} / \mathrm{o}$ visitados los tres sitios.

\section{Sitio 1: LCH1}

Al abordar el cerro desde el sudeste, extremo con escasos afloramientos rocosos, se arriba al espacio que conforma LCH1: un abrigo y sus inmediaciones (Flegenheimer, 1980) (Figura 1E). Las evidencias de la ocupación humana más temprana registrada cuentan con cinco fechados radiocarbónicos que las ubican entre los 11.000 y 10.000 años AP (Flegenheimer, 2004). Este conjunto arqueológico, contenido en la Unidad 3 , incluye escasos restos faunísticos y una importante diversidad tipológica de objetos líticos. Los materiales óseos se limitan a una vértebra y una falange de Lagostomus sp. y una placa fija del caparazón de Eutatus seguini. El conjunto lítico recuperado incluye 475 desechos de talla, nueve núcleos, seis núcleos bipolares, 57 artefactos formatizados y un fragmento de preforma de PCP (Flegenheimer, 2004). La materia prima lítica mayormente seleccionada para su confección fue la cuarcita del Grupo Sierras Bayas (CGSB), en menor proporción la cuarcita Fm. Balcarce (CFB) y en porcentajes mínimos cuarzo, ftanita, caliza silicificada y otras rocas indeterminadas, además de rocas abrasivas y pigmentos minerales (Bayón y Flegenheimer, 2004; Flegenheimer, Bayón, Valente, Baeza y Femenías, 2003; Mazzia, Flegenheimer y Poiré, 2005).

La Unidad 4/5 contiene materiales asignados a diferentes momentos de ocupación humana durante el Holoceno tardío y tiempos históricos, sin fechados absolutos. En este contexto se han recuperado restos óseos de fauna fragmentados. Otros materiales recuperados son tres pigmentos minerales alisados y con estrías de utilización, cuatro tiestos cerámicos, 15 cuentas de vidrio y una importante variedad de artefactos líticos. Entre estos últimos se cuentan 395 desechos de talla, cuatro núcleos bipolares, dos núcleos, cinco artefactos manufacturados por picado, abrasión y pulido y 76 artefactos formatizados. Este último conjunto incluye una importante variedad representada por 21 grupos tipológicos, entre los que se destacan las puntas de proyectil apedunculadas de limbo triangular, cinco pequeñas y una mediana. Para la manufactura del $82 \%$ de estos objetos fue seleccionada la CGSB, en menor medida se utilizó la CFB y en porcentajes mínimos otras materias primas (Mazzia y Flegenheimer, 2007).

\section{Sitio 2: $\mathrm{LCH} 2$}

Desde LCH1, unos $85 \mathrm{~m}$ hacia el oeste-noroeste sobre la misma ladera, pero en posición topográfica más elevada, se encuentra LCH2 (Figura 1F). Es un espacio a cielo abierto limitado por el cerro y por afloramientos de rocas cuarcíticas aislados que le dan forma de un pequeño desfiladero. La utilización más temprana de este espacio se produjo durante el Pleistoceno final, de acuerdo con dos fechados absolutos que brindaron edades entre los 11.000 y 10.000 años AP (Flegenheimer, 2004). Las evidencias materiales contenidas en la Unidad 3 incluyen únicamente objetos líticos. Fueron recuperados 94 desechos de talla, mayormente pequeños y fragmentados, un núcleo y diez artefactos formatizados. Entre estos últimos se cuentan dos PCP, un pequeño instrumento compuesto, dos artefactos con formatización sumaria y cinco fragmentos indiferenciados de artefactos con reducción bifacial de tamaño pequeño 
(Flegenheimer, 2004). En este conjunto se evidencia una selección predominante de la CGSB, seguida por la CFB y un porcentaje mínimo de ftanita y cuarzo; además de pigmentos minerales y rocas abrasivas (Flegenheimer, 2004; Mazzia et al., 2005). Otro momento de ocupación humana de este espacio se identificó en la Unidad 4. La base de esta unidad estratigráfica fue fechada por TL en 4540 años AP, mientras que un carbón cercano al límite con la Unidad 5 dio una edad de $1465 \pm 60$ años AP (Mazzia y Flegenheimer, 2007; Zárate y Flegenheimer, 1991). El conjunto arqueológico es nuevamente escaso e incluye únicamente objetos líticos: 43 desechos de talla, seis núcleos bipolares y cinco artefactos formatizados, entre los que se encuentra una punta de proyectil apedunculada mediana de limbo triangular. La materia prima mayormente representada es la CGSB, seguida por la CFB (Mazzia y Flegenheimer, 2007; Zárate y Flegenheimer, 1991). Finalmente, la ocupación humana más reciente es aquella hallada en la Unidad 5 correspondiente al Holoceno tardío final. Los materiales arqueológicos incluyen molares de Ovis aries, un pigmento mineral, 42 desechos de talla lítica y nueve artefactos líticos formatizados. Entre estos últimos sobresalen cinco puntas de proyectil apedunculadas pequeñas de limbo triangular. La materia prima predominante es nuevamente la CGSB, seguida por un porcentaje mínimo de CFB y ftanita (Zárate y Flegenheimer, 1991). Un fechado absoluto sobre carbón de esta unidad estratigráfica dio una edad de $255 \pm 60$ años AP (Mazzia y Flegenheimer, 2007).

\section{Sitio 3: $\mathrm{LCH} 3$}

Hacia el noroeste, a unos 170 m del sitio LCH2 se localiza LCH3 en una posición topográfica más alta. Este también es un sitio a cielo abierto ubicado en un sector donde el afloramiento del cerro forma un ángulo ofreciendo un reparo de poca altura (Flegenheimer, 1986-1987) (Figura 1G). La ocupación humana más temprana evidenciada en LCH3 ocurrió durante el Pleistoceno final, hace más de 10.500 años AP, de acuerdo con un fechado radiocarbónico realizado sobre una muestra de carbón (Flegenheimer, 1986-1987; Zárate y Flegenheimer, 1991). El conjunto lítico presenta una gran diversidad morfológica e incluye 942 desechos de talla, siete lascas con filos modificados por uso, 100 artefactos formatizados, incluidos 18 núcleos bipolares y 23 núcleos o nucleiformes (Flegenheimer, 1986-1987, 2004). La materia prima mayormente seleccionada para su manufactura fue la CGSB. En proporciones menores también fueron utilizadas rocas como CFB, caliza silicificada, dolomía silicificada, cuarzo y rocas metamórficas indeterminadas. Asimismo, se recuperaron 17 fragmentos de pigmentos minerales y 11 ecofactos, como clastos de basalto muy meteorizado con propiedades abrasivas (Flegenheimer, 1986-1987; Mazzia et al., 2005). En la Unidad 4 se hallaron evidencias de una ocupación humana efímera ocurrida hacia finales del Holoceno medio - Holoceno tardío. No se cuenta con fechados absolutos para este contexto, pero su asignación fue posible mediante la correlación de esta unidad estratigráfica con la Unidad 4 fechada en LCH2. El conjunto arqueológico incluye dos pigmentos minerales con estrías de utilización, 34 desechos de talla lítica, un núcleo y 13 artefactos formatizados. Entre estos últimos se cuentan dos puntas de proyectil apedunculadas medianas con limbo triangular alargado. La materia prima más utilizada fue la CGSB, en menor proporción la CFB y, en un porcentaje mínimo, dolomía silicificada y granodiorita (Flegenheimer, 1986-1987; Mazzia y Flegenheimer, 2007). Por último, la Unidad 5 contiene escasos materiales arqueológicos asignados al Holoceno tardío final por la presencia de fauna introducida. Se trata de un fragmento de bola de boleadora, posiblemente reutilizada como percutor y molares de Ovis aries (Flegenheimer, 19861987; Mazzia y Flegenheimer, 2007).

En suma, este cerro tuvo una importante ocupación en los momentos iniciales de poblamiento del área con sitios bien diferenciados. Dos lugares reparados ( $\mathrm{LCH} 1 \mathrm{y}$ 
LCH3) evidencian un uso intenso y/o recurrente del espacio, y se trata de los dos únicos lugares en toda la microrregión interpretados como ámbitos domésticos con diversidad de actividades. Entre estos dos lugares se encuentra un espacio delimitado por afloramientos rocosos (LCH2), cercano a un manantial, donde se produjo el acorralamiento de presas y la caza utilizando PCP. Las ocupaciones posteriores fueron más efímeras; resulta notable la recurrencia de actividades observadas en LCH2 a lo largo del tiempo.

\section{Sobre el método de análisis y los materiales muestreados}

Tanto los lineamientos que dan sustento a este enfoque arqueométrico (definición de sustancias lipídicas, características de los ácidos grasos y descripción de técnica cromatográfica) como los protocolos empleados y los recaudos metodológicos considerados ya han sido presentados (p. ej. Mazzia, 2013; Mazzia, Brardinelli y Roncaglia, 2017; Mazzia y Flegenheimer, 2015). Por ello, sólo se expondrán sintéticamente en esta oportunidad.

Para los artefactos líticos de más de $8 \mathrm{~cm}$ el protocolo de extracción implicó el escurrimiento de cloroformo directamente sobre las superficies, permitiendo que el solvente arrastrara las sustancias. En tanto para los objetos con medidas menores, las expectativas de obtener la cantidad de grasa necesaria en el muestreo eran limitadas. Por este motivo, se decidió sumergirlas en cloroformo durante 24 horas en agitación intermitente. Por ello, los resultados no provienen solamente de los filos sino de la pieza en su totalidad, e incluyen probablemente una mezcla de las sustancias de las diferentes partes. En ambos casos, los extractos fueron filtrados y concentrados con nitrógeno. Para realizar el análisis de los sedimentos que contenían a los objetos arqueológicos se pesaron $10 \mathrm{gr}$ de cada muestra y se le agregaron $45 \mathrm{ml}$ de cloroformo, dejándolos reposar 24 horas en vasos de precipitación con agitación intermitente. Se los filtró tres veces y se los evaporó a sequedad con nitrógeno. Las extracciones fueron siempre a temperatura ambiente y con suministro de nitrógeno para prevenir el posible deterioro de las muestras de lípidos. Luego, la preparación de ésteres metílicos siguió los siguientes pasos: cada extracto se diluyó en $12,5 \mathrm{ml}$ de solución metílica de hidróxido de potasio en un balón; se conectó a un refrigerante y se puso a hervir durante 12 minutos; se agregaron $25 \mathrm{ml}$ de solución al $5 \%$ de ácido sulfúrico en metanol; el balón se conectó nuevamente a un refrigerante y se puso a hervir durante 12 minutos; al enfriarse se realizó una separación de las fases con una ampolla de decantación de $500 \mathrm{ml}$, utilizando $100 \mathrm{ml}$ de agua destilada y $50 \mathrm{ml}$ de éter de petróleo; se llevó a sequedad en estufa a $90^{\circ} \mathrm{C}$; se diluyó con éter de petróleo y se trasvasó a un vial de inyección; se inyectaron $2 \mu$ en el cromatógrafo gaseoso. Cada paso fue realizado en laboratorios de Materia Hnos. Oleochemicals. El equipo utilizado fue un cromatógrafo gaseoso HP $6890 \mathrm{~N}$ con detector de ionización de Ilama FID e inyector Back automático. Se utilizó una columna capilar Supelcowax 10. La temperatura de la columna fue de $200^{\circ} \mathrm{C}$, la del inyector $250^{\circ} \mathrm{C}$ y la del detector $280^{\circ} \mathrm{C}$.

Mediante estos protocolos se analizaron 28 objetos líticos y dos muestras de sedimentos correspondientes a las ocupaciones humanas más tempranas de LCH1 y LCH3 (Tabla 1; Figuras 2 y 3) y 18 artefactos líticos, un tiesto cerámico y tres muestras de sedimentos asignados a momentos tardíos de ocupación de los tres sitios (Tabla 2; Figuras 4, 5 y 6). Todos los artefactos analizados provienen de excavación estratigráfica y en las condiciones de hallazgo no se registró presencia de pátina o líquenes sobre sus superficies. Los materiales fueron lavados con agua y luego guardados en depósito. Los análisis cromatográficos se realizaron 25 años después de su guardado. 


\begin{tabular}{|c|c|c|c|}
\hline \multicolumn{4}{|c|}{ Ocupaciones tempranas - Unidad 3} \\
\hline Sitio & Muestra & Objeto & Materia prima \\
\hline 䓌 & $\begin{array}{l}35 / 1124 \\
35 / 11504 \\
35 / 12296 \\
35 / 11045 \\
35 / 11003 \\
35 / 1846 \\
35 / 11649 \\
35 / 1864 \\
35 / 1611 \\
35 / 1582 \\
35 / 11225 \\
35 / 12393 \\
35 / 1381\end{array}$ & $\begin{array}{l}\text { raspador de filo alternante fragmentado } \\
\text { instrumento compuesto: perforador y filos laterales alternantes } \\
\text { raedera } \\
\text { raspador agotado } \\
\text { raedera de filos convergentes } \\
\text { forma base bifacial fragmentada } \\
\text { artefacto con retoques sumarios } \\
\text { instrumento compuesto: raedera y punta entre muescas } \\
\text { raedera con dorso } \\
\text { instrumento incompleto } \\
\text { instrumento compuesto: raedera doble convergente y posible raspador reutilizado } \\
\text { artefacto con retoques sumarios } \\
\text { artefacto bifacial de bisel asimétrico fragmentado }\end{array}$ & $\begin{array}{l}\text { CGSB } \\
\text { ftanita } \\
\text { CGSB } \\
\text { CGSB } \\
\text { CGSB } \\
\text { CGSB } \\
\text { CGSB } \\
\text { CGSB } \\
\text { CGSB } \\
\text { CGSB } \\
\text { CGSB } \\
\text { CFM } \\
\text { caliza silicificada }\end{array}$ \\
\hline$\stackrel{m}{\stackrel{m}{\leftrightarrows}}$ & $\begin{array}{l}35 / 365 \\
35 / 3858 \\
35 / 3966 \\
35 / 31673 \\
35 / 3900 \\
35 / 329 \\
35 / 3853 \\
35 / 3145 \\
35 / 31435 \\
35 / 3695 \\
35 / 31358 \\
35 / 390 \\
35 / 31800 \\
35 / 3250 \\
35 / 3969\end{array}$ & $\begin{array}{l}\text { perforador } \\
\text { posible cepillo } \\
\text { raedera doble lateral } \\
\text { lasca angular inclinada } \\
\text { núcleo bipolar } \\
\text { núcleo bipolar } \\
\text { artefacto con retoques sumarios } \\
\text { artefacto con retoques sumarios } \\
\text { muesca } \\
\text { cuchillo de filo festoneado lateral largo } \\
\text { raedera lateral doble fragmentada } \\
\text { artefacto con retoques sumarios } \\
\text { pieza nucleiforme } \\
\text { núcleo bipolar } \\
\text { artefacto mediano pequeño de bisel oblicuo }\end{array}$ & $\begin{array}{l}\text { CGSB } \\
\text { CGSB } \\
\text { CGSB } \\
\text { dolomía silicificada } \\
\text { CGSB } \\
\text { CGSB } \\
\text { CGSB } \\
\text { CGSB } \\
\text { roca metamórfica indeterminada } \\
\text { CGSB } \\
\text { CGSB } \\
\text { CGSB } \\
\text { caliza silicificada } \\
\text { caliza silicificada } \\
\text { caliza silicificada }\end{array}$ \\
\hline
\end{tabular}

Tabla 1. Descripción de artefactos analizados provenientes de la Unidad 3.

\section{Sobre los resultados obtenidos en cada contexto}

Una vez obtenido el cromatograma resultante de cada inyección en el cromatógrafo gaseoso, se determinó el porcentaje de cada ácido graso en relación con el total existente en la muestra; esos valores se presentan en las Tablas 3 a 7 . Estos porcentajes y las relaciones entre ellos fueron utilizados a la hora de interpretar los resultados usando bases de datos de referencia tanto de recursos actuales como de investigaciones arqueológicas y de experimentaciones propias.

\section{De los grupos tempranos}

Del conjunto asignado a los primeros grupos que habitaron $\mathrm{LCH} 1$ se analizaron 13 muestras. Los resultados se detallan en la Tabla 3, junto con los resultados de una muestra de sedimentos de la Unidad 3. La muestra de grasa extraída de la matriz sedimentaria resultó apenas suficiente para ser detectada por el cromatógrafo gaseoso; 


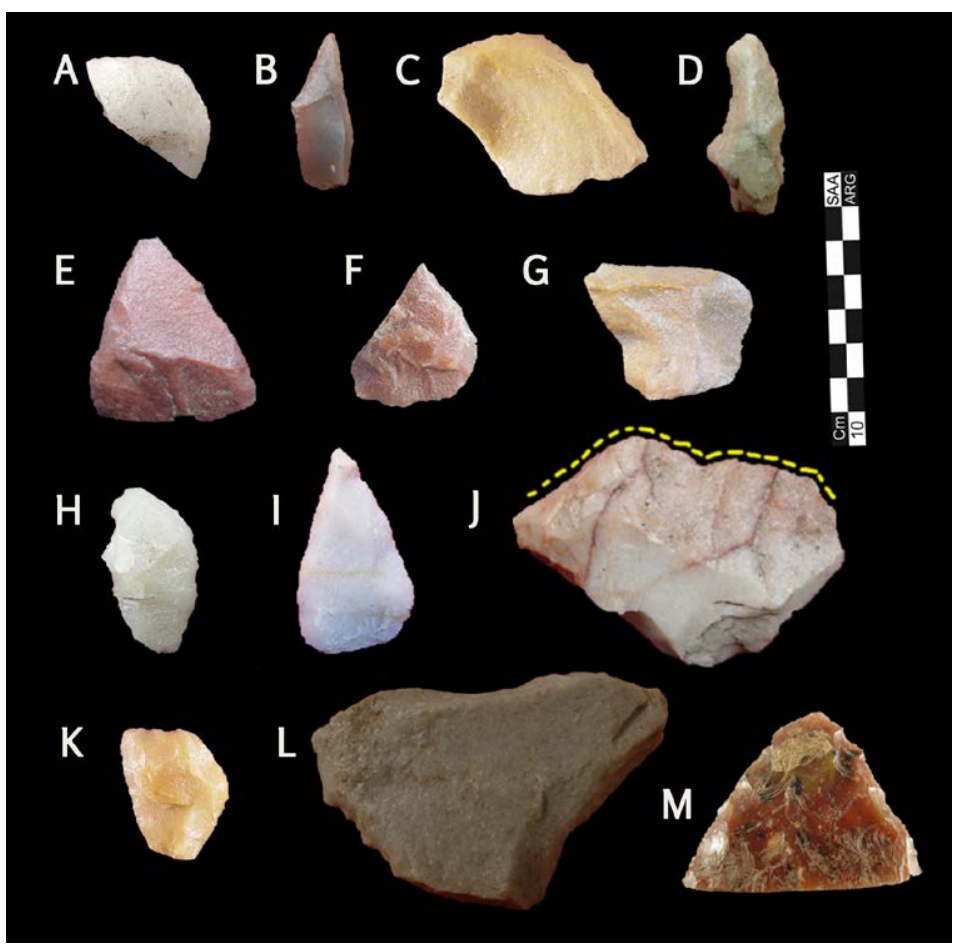

Figura 2. Artefactos líticos analizados provenientes de la Unidad 3 de $\mathrm{LCH} 1$. Referencias: A) 35/1 124;B) 35/1 381; C) 35/1 582; D) 35/1 611; E) 35/1 846; F) 35/1 864; G) 35/1 1003; H) 35/1 1045; I) 35/1 1225; J) 35/1 1504; K) 35/1 1649; L) 35/1 2296; M) 35/1 2393.

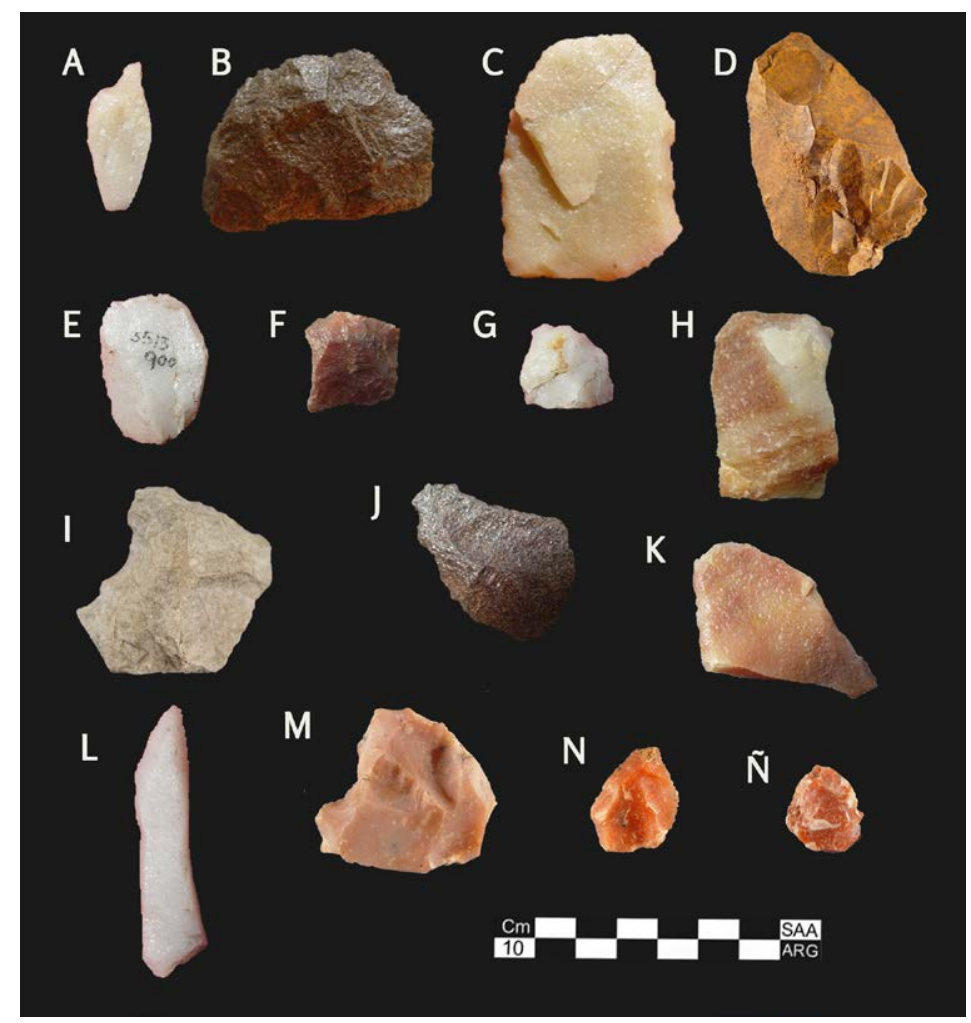

Figura 3. Artefactos líticos analizados provenientes de la Unidad 3 de LCH3. Referencias: A) $35 / 3$ 29;B) $35 / 3$ 65; C) 35/3 90; D) 35/3 145; E) 35/3 695; F) 35/3 853; G) 35/3 858; H) $35 / 3$ 900; I) $35 / 3$ 966; J) 35/3 1358; K) 35/3 969; L) 35/3 250; M) 35/3 1673; N) 35/3 1435. 


\begin{tabular}{|c|c|c|c|}
\hline \multicolumn{4}{|c|}{ Ocupaciones tardías - Unidad 4 y Unidad $4 / 5$} \\
\hline Sitio & Muestra & Objeto & Materia prima \\
\hline 寽 & $\begin{array}{l}35 / 12003 \\
35 / 11664 \\
35 / 1946 \\
35 / 11054 \\
35 / 11887 \\
35 / 11665 \\
35 / 1363 \\
35 / 11985 \\
35 / 11174 \\
35 / 12001 \\
35 / 12118\end{array}$ & $\begin{array}{l}\text { molino de mano simple } \\
\text { instrumento compuesto: yunque y sobador } \\
\text { núcleo bipolar } \\
\text { artefacto con retoques sumarios } \\
\text { raedera lateral bifacial fragmentada } \\
\text { raedera denticulada lateral de filo festoneado alternante } \\
\text { artefacto con retoques sumarios } \\
\text { punta entre muescas } \\
\text { cepillo de filo irregular frontal } \\
\text { raedera lateral con filo alternante } \\
\text { tiesto }\end{array}$ & $\begin{array}{l}\text { CFM } \\
\text { CFM } \\
\text { CGSB } \\
\text { CGSB } \\
\text { ftanita } \\
\text { CGSB } \\
\text { pórfiro cuarcítico } \\
\text { CFM } \\
\text { indeterminada } \\
\text { CGSB } \\
\text { cerámica }\end{array}$ \\
\hline 꼰 & $\begin{array}{l}35 / 238 \\
35 / 235 \\
35 / 225\end{array}$ & $\begin{array}{l}\text { Instrumento compuesto fragmentado: filo con muesca y filo de raedera } \\
\text { núcleo bipolar } \\
\text { núcleo bipolar }\end{array}$ & $\begin{array}{l}\text { CGSB } \\
\text { CGSB } \\
\text { CGSB }\end{array}$ \\
\hline 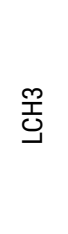 & $\begin{array}{l}35 / 31491 \\
35 / 3758 \\
35 / 31863 \\
35 / 31516 \\
35 / 314\end{array}$ & $\begin{array}{l}\text { cepillo de filo extendido } \\
\text { raedera de filo fronto-lateral convergente en ápice romo } \\
\text { pieza foliácea } \\
\text { cuchillo de filo natural frontal con dorso formatizado } \\
\text { raspador }\end{array}$ & $\begin{array}{l}\text { CFM } \\
\text { CGSB } \\
\text { CGSB } \\
\text { CGSB } \\
\text { CGSB }\end{array}$ \\
\hline
\end{tabular}

Tabla 2. Descripción de artefactos analizados provenientes de la Unidad 4 y Unidad 4/5.

el cromatograma muestra tres picos con áreas muy pequeñas. De esta forma, se considera que los resultados alcanzados en el análisis de las piezas arqueológicas son válidos para realizar inferencias sobre sus usos en el pasado, puesto que no existen evidencias sobre su contaminación con las sustancias presentes en los sedimentos.

Entre los 13 artefactos, solamente dos (35/1 1003 y 35/1 2393) no brindaron muestras de grasas suficientes para ser detectadas y los cromatogramas resultantes quedaron en blanco. Este hecho puede entenderse de dos formas: que los objetos no hayan sido utilizados o bien que las posibles sustancias que podrían haber quedado no perduraron a lo largo del tiempo.

El extracto 35/1 124 proviene de un raspador sobre CGSB. Los valores relativos con los que fueron detectados los ácidos mirístico, palmítico, oleico, linoleico y á-linolénico semejan a aquellos descriptos para grasas de origen animal terrestre (Robinson, Calvo Rebollar y Sevillano Calvo, 1991; United States Testing Company, Inc., 1955, tabla 9, pp. 28-29). Sin embargo, el ácido esteárico presenta un valor cercano al $30 \%$, excesivo para las composiciones naturales, pudiendo enriquecerse por la degradación de ácidos grasos más inestables. Asimismo, la presencia de los ácidos grasos C20:2 y C22:2 no concuerda con un origen animal. Entre las muestras experimentales (Mazzia, 2010-2011) se detectó un valor comparable para el ácido esteárico en piezas con mástic, en tanto que el ácido docosadienoico pudo encontrarse únicamente en muestras experimentales usadas sobre madera y vegetales frescos. Puesto que la muestra proviene de toda la superficie del artefacto, es posible que estemos frente a la mezcla de grasas de origen animal producto del uso del raspador, con aceites vegetales relacionados con el enmangue de la pieza.

El conjunto de ácidos grasos identificados en la muestra 35/1 1504, si bien menos diverso, presenta una situación similar a la anterior. En este caso la relación existente 
entre los porcentajes de los ácidos mirístico, palmítico, esteárico, oleico y linoleico son comparables a los presentes en grasas de origen animal terrestre (Robinson et al., 1991; United States Testing Company, Inc., 1955, tabla 9, pp. 28-29). En tanto, la identificación de los ácidos eicosadienoico y docosadienoico con más del $5 \%$ es consistente con la posibilidad de que la pieza haya sido enmangada. El conjunto lipídico obtenido de este instrumento compuesto sugiere que el mismo fue utilizado en el pasado sobre recursos animales terrestres y que su manipulación pudo estar mediada por un enmangue.

Los resultados obtenidos a partir de la muestra 35/1 2393 no permiten realizar interpretaciones certeras dado que los ácidos grasos detectados son pocos y con proporciones que sugieren que las sustancias se vieron afectadas por procesos de degradación. Este hecho puede notarse a partir de la ausencia de ácidos grasos de cadena muy larga y de la presencia de solamente el $3 \%$ de ácidos grasos poliinsaturados, características que hacen que un ácido graso resulte más inestable y proclive a degradarse con el tiempo y la acción de factores externos (Bondia Pons, 2007; Evershead, Heron, Charters y Goad, 1992). Una situación similar pudo detectarse en los extractos 35/1 1649 y 35/1 864. A pesar de que ambos objetos líticos brindaron conjuntos lipídicos, éstos no son considerados confiables para realizar inferencias sobre los posibles usos que las personas le hayan dado en el pasado.

La muestra 35/1 1045 posee valores relativos de ácido palmítico, esteárico, oleico, linoleico y á-linolénico que únicamente pueden ser comparados con las composiciones de grasas animales terrestres. En las bases de datos de referencia pueden encontrarse porcentajes semejantes en los conjuntos lipídicos de carne vacuna, ovina y en grasas de cerdo (United States Testing Company, Inc., 1955, tabla 9, pp. 28-29). Sin embargo, estos porcentajes relativos no coinciden con ninguna de las composiciones de ácidos grasos provenientes de carne cruda de recursos animales nativos de interés arqueológico, como guanaco, vizcacha, coipo y bagre (Frère, Constenla, Bayón y González, 2010). Por lo tanto, puede sostenerse que las personas que confeccionaron este raspador destinaron su uso exclusivamente para el procesamiento de recursos animales terrestres, aunque no puede precisarse un origen específico.

Con la sigla $35 / 1846$ se identifica a una forma base bifacial fragmentada, cuya fractura posiblemente se habría producido durante la manufactura de una punta. Es posible que por este motivo quien la talló le haya dado otro destino. De acuerdo con los resultados, esta forma base fue utilizada sobre recursos orgánicos en lugar de ser descartada. La proporción en la que se encuentran los ácidos palmítico, esteárico, oleico y linoleico es semejante a las composiciones de grasas animales, a pesar del valor elevado del ácido esteárico (Robinson et al., 1991; United States Testing Company, Inc., 1955, tabla 9, pp. 28-29). Existe la posibilidad de que este enriquecimiento en el ácido esteárico sea producto de la degradación del ácido linoleico, que por lo tanto podría haber tenido un porcentaje mayor. A esto puede sumarse la presencia de los ácidos C20:2 y C22:2, sólo identificados en aceites vegetales. De esta forma, puede considerarse la existencia de una mezcla de lípidos de diferentes orígenes resultado de los diferentes recursos orgánicos con los que este objeto ha estado en contacto directo.

Otra de las piezas analizadas clasificada como una raedera con dorso (35/1 611) rindió una muestra pequeña en la que se identificaron seis ácidos grasos. Sin embargo, resulta llamativo que el porcentaje relativo detectado de ácido docosadienoico es muy similar al del ácido esteárico, y ambos resultan dominantes en la composición. Aún no se ha podido elaborar una explicación para estos valores.

Los últimos tres extractos fueron los más abundantes del conjunto y los que presentaron mayor diversidad de ácidos grasos. La muestra 35/1 582 procede de un instrumento incompleto sobre CGSB, cuyo tamaño permitió sumergir en el solvente 
únicamente el filo. Aproximadamente el $5 \%$ de la composición total corresponde a ácidos grasos con número impar de átomos de carbono, resultantes mayormente de la acción bacteriana sobre las sustancias (Buonasera, 2007; Robinson et al., 1991). La relación existente entre los valores de los ácidos palmítico, esteárico, oleico, linoleico y á-linolénico resulta comparable con las composiciones de grasas animales terrestres (Robinson et al., 1991; United States Testing Company, Inc., 1955, tabla 9, pp. 28-29), aunque nuevamente el porcentaje del ácido esteárico cercano al $30 \%$ podría estar enmascarando evidencias de aceites vegetales; efectivamente, el registro de los ácidos C20:2 y C22:2 refuerza esta posibilidad. En suma, el filo apenas formatizado de este objeto lítico fue utilizado para el procesamiento de recursos orgánicos que pudieron haber incluido tanto especies de origen animal como vegetal.

A partir del instrumento compuesto $35 / 11225$ se obtuvo $5 \%$ de diferentes ácidos grasos con número impar de átomos de carbono en su cadena, lo que evidencia una importante actividad bacteriana sobre las sustancias (Buonasera, 2007). Una particularidad de esta muestra es la presencia del ácido nonanoico. Este ácido graso no está presente en la naturaleza, ya que se forma como producto de la oxidación de los ácidos C18:1, C18:2 y C18:3. Se lo encuentra frecuentemente como componente de los aceites vegetales rancios o como resultado de la descomposición de las sustancias post-descarte (Babot, Mazzia y Bayón, 2007; Buonasera, 2007). Otra particularidad es el registro del ácido heneicosadienoico con un valor relativo de 4,4\%: este ácido no está en las bases de datos consultadas, pero sí fue identificado en la muestra experimental de vegetales frescos con más del 9\% (Mazzia, 2010-2011). Además, las relaciones entre los valores relativos de los ácidos palmítico, esteárico, oleico y linoleico resultan comparables a las composiciones de grasas animales terrestres (Robinson et al., 1991; United States Testing Company, Inc., 1955, tabla 9, pp. 28-29). La muestra en conjunto evidencia una mezcla de orígenes vegetales y animales. Como este objeto ha sido sumergido completamente en el solvente, no es posible distinguir si la mezcla se debe a que el instrumento fue usado indistintamente sobre toda clase de recurso o si sus distintas partes tuvieron una utilización específica y diferente.

Finalmente, el registro lipídico obtenido a partir de 35/1 381 presenta características semejantes al descripto para la muestra anterior. Los valores relativos detectados para los ácidos mirístico, palmítico, esteárico, oleico y linoleico son comparables a las composiciones de grasas animales (Robinson et al., 1991; United States Testing Company, Inc., 1955, tabla 9, pp. 28-29). En este caso también se identificaron los ácidos $\mathrm{C} 21: 2$ y C22:2 pero con registros menores al $2 \%$. Estos dos ácidos grasos podrían indicar un aporte menor de lípidos de origen vegetal. De esta forma, este artefacto sobre bifaz de caliza silicificada no solamente fue trasladado por distancias que superan los $400 \mathrm{~km}$ (Flegenheimer et al., 2003), sino que además fue utilizado en contacto con recursos orgánicos de origen animal y, posiblemente, también vegetal.

No se realizaron análisis de sustancias grasas sobre piezas del conjunto asignado a quienes visitaron $\mathrm{LCH} 2$ durante el Pleistoceno final porque, a excepción de las PCP, los artefactos son de tamaños muy pequeños o se encuentran fragmentados.

En cambio, se seleccionaron 15 objetos líticos del conjunto temprano de LCH3 para su análisis cromatográfico. Los resultados se encuentran detallados en la Tabla 4, junto con la composición lipídica presente en una muestra de sedimento de la Unidad 3. El extracto obtenido a partir de los sedimentos fue muy pequeño, y se detectaron en el mismo solamente tres ácidos grasos en proporciones ínfimas. En la tabla, los porcentajes de estos ácidos grasos son altos porque representan valores relativos al total de la muestra. De esta forma, se considera que los resultados obtenidos a partir de las muestras arqueológicas no fueron contaminados por sustancias presentes en la matriz. 


\begin{tabular}{|c|c|c|c|c|c|c|c|c|c|c|c|c|c|c|}
\hline \multirow{2}{*}{ Ácido graso } & \multicolumn{14}{|c|}{ Muestra 35/1 - Unidad 3} \\
\hline & Sed & 124 & 1504 & 2296 & 1045 & 1003 & 846 & 1649 & 864 & 611 & 582 & 1225 & 2393 & 381 \\
\hline C9:0 - Á. nonanoico & - & - & - & - & - & - & - & - & - & - & - & 0,39 & - & - \\
\hline C10:0 - Á. cáprico & - & - & - & - & - & - & 0,38 & - & - & - & - & 0,25 & - & - \\
\hline $\begin{array}{l}\text { C11:0 - Á. } \\
\text { undecanoico }\end{array}$ & - & - & - & - & - & - & - & - & - & - & 0,15 & 0,3 & - & - \\
\hline C12:0 - Á. láurico & - & 0,10 & - & - & - & - & 0,27 & - & - & - & 0,12 & - & - & - \\
\hline $\begin{array}{l}\text { C13:0 - Á. } \\
\text { tridecanoico }\end{array}$ & - & - & - & - & - & - & - & - & - & - & - & 0,38 & - & - \\
\hline C14:0 - Á. mirístico & - & 3,89 & 3,25 & 2,31 & 0,37 & - & 0,95 & 0,53 & 2,94 & 1,6 & 3,02 & 4,43 & - & 4,84 \\
\hline $\begin{array}{l}\text { C14:1 - Á. } \\
\text { miristoleico }\end{array}$ & - & 0,58 & 0,39 & - & - & - & - & - & 0,42 & - & 0,5 & 0,14 & - & 0,71 \\
\hline $\begin{array}{l}\text { C15:0 - Á. } \\
\text { pentadecanoico }\end{array}$ & - & 1,72 & 1,11 & - & 0,39 & - & 0,63 & - & 0,69 & - & 0,74 & 1,57 & - & 1,67 \\
\hline C16:0 - Á. palmítico & 15,97 & 20,59 & 18,48 & 16,71 & 16,78 & - & 17,25 & 16,81 & 23,37 & 12,03 & 23,68 & 19,1 & - & 20,44 \\
\hline $\begin{array}{l}\text { C16:1 - Á. } \\
\text { palmitoleico }\end{array}$ & - & 2,06 & 1,63 & 1,31 & 1,7 & - & 1,74 & 2,03 & 2,17 & - & 2,64 & 3,35 & - & 3,85 \\
\hline $\begin{array}{l}\text { C17:0 - Á. } \\
\text { heptadecanoico }\end{array}$ & - & 2,56 & - & 2,39 & 2,56 & - & 2,48 & 2,36 & 2,39 & - & 2,91 & 1,89 & - & 2,52 \\
\hline $\begin{array}{l}\text { C17:1 - Á. } \\
\text { heptadecenoico }\end{array}$ & - & 0,52 & - & - & 0,66 & - & 0,54 & - & - & - & 0,72 & 1,16 & - & 0,89 \\
\hline C18:0 - Á. esteárico & 48,09 & 29,75 & 25,38 & 41,22 & 27,6 & - & 35,84 & 37,74 & 34,34 & 32,76 & 31,47 & 17,59 & - & 21,42 \\
\hline C18:1 - Á. oleico & 35,93 & 25,02 & 23,74 & 33,1 & 43,17 & - & 25,44 & 37,47 & 29,21 & 17,77 & 19,22 & 23,33 & - & 31,67 \\
\hline C18:2 - Á. linoleico & - & 2,31 & 2 & 2,95 & 3,05 & - & 2,88 & 3,06 & 3,03 & - & 3,67 & 1,96 & - & 2,55 \\
\hline $\begin{array}{l}\text { C18:3n3 - Á. } \\
\text { á-linolénico }\end{array}$ & - & 0,42 & - & - & 0,61 & - & - & - & - & - & 0,25 & 0,17 & - & 0,17 \\
\hline $\begin{array}{l}\text { C18:4 - Á. } \\
\text { octadecatetraenoico }\end{array}$ & - & 1,06 & 2,74 & - & 0,91 & - & 1,91 & - & - & - & 1,45 & 1,95 & - & 2 \\
\hline $\begin{array}{l}\text { C19:0 - Á. } \\
\text { nonadecanoico }\end{array}$ & - & 0,24 & - & - & 0,21 & - & - & - & - & - & 0,26 & 0,22 & - & 0,25 \\
\hline C20:0 - Á. araquídico & - & 0,42 & - & - & 0,33 & - & - & - & - & - & 0,68 & 0,8 & - & 0,55 \\
\hline C20:1- Á. eicosenoico & - & - & - & - & - & - & - & - & - & - & - & - & - & 0,71 \\
\hline $\begin{array}{l}\text { C20:2 - Á. } \\
\text { eicosadienoico }\end{array}$ & - & 3,61 & 6,05 & - & 1,13 & - & 3,27 & - & - & 6,41 & 3,37 & 3,31 & - & 1,67 \\
\hline $\begin{array}{l}\text { C21:2 - Á. } \\
\text { heneicosadienoico }\end{array}$ & - & - & - & - & - & - & - & - & - & - & - & 4,44 & - & - \\
\hline $\begin{array}{l}\text { C22:2 - Á. } \\
\text { docosadienoico }\end{array}$ & - & 3,03 & 5,55 & - & - & - & 5,16 & - & - & 29,43 & 2,96 & 5,13 & - & 1,64 \\
\hline NN & - & 2,13 & 9,67 & - & 0,53 & - & 1,26 & - & 1,42 & - & 2,22 & 8,03 & - & 2,45 \\
\hline
\end{tabular}

Tabla 3. Resultados expresados en porcentaje de la composición de ácidos grasos de la muestra de grasa extraída de las piezas arqueológicas de LCH1 y de matriz sedimentaria de la Unidad 3. Referencias: Sed = sedimento.

Entre las 15 piezas bajo análisis solamente una no brindó la cantidad suficiente de grasa para ser detectada, por lo que el cromatograma resultante quedó en blanco. Se trata de la muestra $35 / 390$ obtenida de la superficie de un artefacto con retoques sumarios sobre CGSB. Las siguientes muestras fueron extraídas de dos artefactos clasificados originalmente como núcleos bipolares. La muestra 35/3 900 evidencia un registro lipídico abundante y variado. En este registro resulta notable la total ausencia de ácido linoleico y sí se encuentran presentes dos ácidos grasos más inestables que éste, C18:3n3 y C18:4. Es posible que el ácido linoleico se haya degrado a lo largo del tiempo, pero, de haberlo hecho, igualmente no se encontraría en grandes cantidades en la composición original. De ser así, la relación existente entre los valores relativos de los ácidos palmítico, esteárico, oleico y un valor pequeño de ácido linoleico resulta comparable a las composiciones de 
grasas de origen animal (Robinson et al., 1991; United States Testing Company, Inc., 1955, tabla 9, pp. 28-29). El ácido eicosadienoico (20:1) es indicativo de un pequeño aporte de aceites vegetales. La muestra 35/3 29 también presenta proporciones semejantes a aquellas que caracterizan a las grasas animales entre los ácidos grasos C14:0, C16:0, C18:0. C18:1 y C18:2. Al mismo tiempo, la composición de esta sustancia arqueológica contiene tres ácidos grasos - eicosadienoico, heneicosenoico y docosadienoico detectados únicamente en aceites vegetales en las muestras experimentales (Mazzia, 2010-2011). En suma, puede proponerse que estos dos artefactos fueron utilizados en el pasado para tareas relacionadas con el procesamiento de recursos orgánicos tanto de origen animal como vegetal.

El conjunto muestreado incluyó tres artefactos manufacturados sobre caliza silicificada. Se trata de un núcleo bipolar (35/3 250), una pieza nucleiforme $(35 / 31800)$ y un artefacto mediano pequeño de bisel oblicuo (35/3 969). Los resultados de la muestra $35 / 3250$ resultan singulares al compararlos con los de todas las muestras descriptas hasta el momento. Predominan dos ácidos grasos poco comunes: C18:3n3 y C21:2; aún menos común resulta su alto valor relativo. El ácido heneicosadienoico no es descripto en las bases de datos de grasas conocidas (p. ej. Frère et al., 2010; Robinson et al., 1991; United States Testing Company, Inc., 1955, tabla 9, pp. 28-29) pero fue identificado en la muestra experimental utilizada sobre vegetales (Mazzia, 2010-2011). Por su parte, el ácido á-linolénico suele ser un componente menor de lípidos animales y vegetales (en general no supera el $2 \%$ ), pero en este caso su registro sobrepasa al de los ácidos esteárico, oleico y linoleico; tal relación solamente ha sido descripta en semillas (Robinson et al., 1991; United States Testing Company, Inc., 1955, tabla 9, pp. 28-29). Por lo tanto, este núcleo bipolar de caliza silicificada posiblemente fue utilizado para el procesamiento de semillas. En la muestra $35 / 31800$ se ha registrado una cantidad relativa de los ácidos mirístico, palmítico, esteárico, oleico y linoleico comparable a la identificada comúnmente con grasas de origen animal (Robinson et al., 1991; United States Testing Company, Inc., 1955, tabla 9, pp. 28-29); con la salvedad de que en este caso existe un enriquecimiento del ácido esteárico, probablemente debido a la degradación de los ácidos linoleico y á-linolénico. Además, en esta muestra se han detectado los ácidos grasos 20:2, C21:1 y C22:2 en proporciones semejantes a las presentes en la muestra experimental utilizada sobre vegetales (Mazzia, 20102011). Por este motivo, se considera que en la superficie de esta pieza nucleiforme de caliza silicificada se conservó una mezcla de sustancias de origen vegetal y animal. El registro lipídico identificado en la muestra 35/3 969 es consistente con un origen animal de las sustancias recuperadas de acuerdo con los valores relativos de los ácidos grasos C14:0, C16:0, C18:0, C18:1 y C18:2 (Robinson et al., 1991; United States Testing Company, Inc., 1955, tabla 9, pp. 28-29).

Los resultados obtenidos a partir de las muestras 35/3 145 y 35/3 695 no permiten interpretaciones más allá de que ambas fueron utilizadas sobre recursos orgánicos que dejaron sustancias grasas en sus porosidades y micro fracturas. No es posible inferir el origen de estas sustancias ya que presentan un marcado predominio de los ácidos palmítico y esteárico, ampliamente distribuidos en la naturaleza y cuyo enriquecimiento puede deberse a la degradación de ácidos grasos más inestables.

La muestra 35/3 966 fue extraída de una raedera doble lateral que fue hallada fracturada in situ. (Flegenheimer, 1986-1987). En los valores relativos se observa, al igual que en las dos muestras anteriores, una presencia excesiva del ácido esteárico, que alcanza un $40 \%$. Un predominio tan marcado no ha sido registrado en ninguna composición natural original, por lo que es interpretado como el producto de la degradación de otros ácidos grasos más inestables. A pesar de ello, la proporción de los ácidos grasos 20:2, 21:2 y 22:2 puede ser indicativa de un origen vegetal de acuerdo con los resultados obtenidos en las muestras experimentales (Mazzia, 2010-2011). De esta forma, puede proponerse 
que esta raedera fue usada sobre recursos de origen vegetal, aunque posiblemente hayan existido grasas de otro origen en contacto con la pieza.

La única muestra en este conjunto en la que se registró el ácido nonanoico es la $35 / 365$. Este es un ácido graso poco frecuente que se origina en la oxidación de los ácidos grasos C18:1, C18:2 y C18:3 y suele ser un componente de los aceites de semillas rancios. Se lo relaciona con la descomposición de las sustancias posterior al descarte de los instrumentos (Babot et al., 2007; Buonasera, 2007). Se destacan también los valores relativos identificados para los ácidos á-linolénico y estearidónico, para los cuales solamente se encontraron correlatos en las composiciones de aceites de semillas (Robinson et al., 1991; United States Testing Company, Inc., 1955, tabla 9, pp. 28-29). Además, los ácidos grasos C20:2 y C22:2 fueron detectados únicamente en los registros de las muestras experimentales de vegetales y madera (Mazzia, 20102011). Puede sostenerse que este perforador fue utilizado en el pasado sobre recursos de origen vegetal, lo que incluiría el procesamiento de semillas.

En el cromatograma resultante del análisis de la muestra $35 / 3858$ se detectaron valores relativos de los ácidos palmítico y palmitoleico comparables a aquellos descriptos en carnes de mamíferos marinos (Patrick, de Koning y Smith, 1985). Lo mismo sucede con el ácido estearidónico, con la diferencia de que éste ha sido identificado con valores relativos similares no solamente en las carnes de mamíferos marinos, sino también en pescados y semillas (Patrick et al., 1985; Robinson et al., 1991; Sengör, Özden, Erkan, Tüter y Ayse Aksoy, 2003). Los ácidos grasos C20:2 y C22:2 fueron registrados con porcentajes próximos al $8 \%$. Esta proporción sólo ha sido observada en las composiciones lipídicas de las muestras experimentales de vegetales frescos y madera (Mazzia, 20102011). Entonces, el uso de este posible cepillo pudo haber estado relacionado con el procesamiento de recursos animales de origen marino y recursos vegetales. Un registro lipídico similar al anterior fue obtenido a partir de la muestra 35/3 1673. Además de los valores relativos de los ácidos grasos C16:0, C16:1, C18:4, C20:2 y C22:2 comparables a los de la muestra $35 / 3858$, en este caso se ha registrado un porcentaje de más del $10 \%$ en el ácido linoleico. Este último dato refuerza la identificación de lípidos de origen vegetal (Rottländer, 1990). De esta forma, se propone que esta lasca de dolomía silicificada fue incluida en labores relacionadas con el procesamiento de recursos vegetales, y posiblemente también de recursos animales de origen marino.

En la muestra $35 / 31435$, obtenida de una muesca, los resultados cromatográficos revelan valores relativos de los ácidos palmítico y palmitoleico similares a los valores presentes en carnes de mamíferos marinos (Patrick et al., 1985). El ácido estearidónico también apunta en esa dirección, aunque además de ser identificado en proporciones semejantes en las carnes de mamíferos marinos, es posible detectarlo en pescados y semillas (Muhamad y Mohamad, 2012; Patrick et al., 1985; Robinson et al., 1991; Sengör et al., 2003). Este artefacto probablemente haya sido usado en faenas que implicaron su contacto directo con grasas de origen animal marino.

Los resultados de 35/3 853 muestran una relación entre los valores relativos de los ácidos palmítico, esteárico, oleico y linoleico que resulta comparable a las composiciones de grasas de animales terrestres (Robinson et al., 1991; United States Testing Company, Inc., 1955, tabla 9, pp. 28-29). Además, se destaca la presencia de ácidos grasos con número impar de átomos de carbono en su estructura molecular, relacionados con la acción bacteriana sobre las sustancias (Buonasera, 2007). Puede proponerse que el uso de este artefacto con retoques sumarios estuvo asociado principalmente al procesamiento de recursos animales terrestres.

Por último, se analizó una raedera lateral doble fragmentada (35/3 1358), cuyos resultados evidencian la mezcla de lípidos de diferentes orígenes. Por un lado, los porcentajes 
relativos al total de los ácidos palmítico, esteárico, oleico y linoleico son semejantes a los que se encuentran en las composiciones de grasas de animales terrestres (Robinson et al., 1991; United States Testing Company, Inc., 1955, tabla 9, pp. 28-29). Por otro lado, los ácidos grasos C20:2 y C22:2 fueron identificados en forma conjunta solamente en las muestras experimentales obtenidas del uso de objetos líticos sobre vegetales frescos y madera (Mazzia, 2010-2011). De esta forma, proponemos que esta raedera fue usada para el procesamiento de recursos orgánicos tanto vegetales como animales, dejando como resultado una mezcla de composiciones lipídicas diferentes.

\begin{tabular}{|c|c|c|c|c|c|c|c|c|c|c|c|c|c|c|c|c|}
\hline \multirow{2}{*}{ Ácido graso } & \multicolumn{16}{|c|}{ Muestra LCH3 - Unidad 3} \\
\hline & Sed & 65 & 858 & 966 & 1673 & 900 & 29 & 853 & 145 & 1435 & 695 & 1358 & 90 & 1800 & 250 & 969 \\
\hline C9:0 - Á. nonanoico & - & 0,16 & - & - & - & - & - & - & - & - & - & - & - & - & - & - \\
\hline C10:0 - Á. cáprico & - & - & - & - & - & 0,03 & - & - & - & - & - & - & - & - & - & - \\
\hline C12:0 - Á. láurico & - & 0,07 & - & - & - & - & 0,08 & 0,08 & - & 0,08 & - & - & - & - & - & 0,49 \\
\hline $\begin{array}{l}\text { C13:0 - Á. } \\
\text { tridecanoico }\end{array}$ & - & - & - & - & - & 0,08 & - & - & - & 0,09 & - & - & - & - & - & 0,01 \\
\hline C14:0 - Á. mirístico & - & 1,66 & 1,22 & 1,11 & 1,1 & 3,57 & 2,19 & 8,47 & 3,88 & 6,22 & 3,73 & 3,45 & - & 3,62 & 1,41 & 2,93 \\
\hline $\begin{array}{l}\text { C14:1 - Á. } \\
\text { miristoleico }\end{array}$ & - & 0,26 & - & 0,12 & - & 0,68 & 0,36 & 1,36 & 0,57 & 0,4 & - & 0,47 & - & 0,53 & 0,31 & 0,49 \\
\hline $\begin{array}{l}\text { C15:0 - Á. } \\
\text { pentadecanoico }\end{array}$ & - & 0,92 & 1,49 & 0,62 & 1,52 & 1,66 & 1,05 & 1,87 & 1,46 & 4,11 & 1,44 & 1,47 & - & 0,99 & 0,88 & 1,06 \\
\hline C16:0 - Á. palmítico & 27,81 & 17,9 & 19,86 & 13,46 & 15,84 & 22,22 & 19,72 & 22,81 & 28,85 & 25,51 & 27,69 & 20,6 & - & 18,57 & 12,96 & 22,51 \\
\hline $\begin{array}{l}\text { C16:1 - Á. } \\
\text { palmitoleico }\end{array}$ & - & 1,47 & 4,05 & - & 5,28 & 1,69 & 2,06 & 2,17 & 2,43 & 11,02 & 4,87 & 2,01 & - & 1,94 & - & 2,79 \\
\hline $\begin{array}{l}\text { C17:0 - Á. } \\
\text { heptadecanoico }\end{array}$ & - & 2,51 & 2,77 & 1,86 & 1,95 & 2,63 & 2,61 & 2,44 & 3,09 & 2,59 & - & 2,54 & - & 2,29 & 1,56 & 2,52 \\
\hline $\begin{array}{l}\text { C17:1 - Á. } \\
\text { heptadecenoico }\end{array}$ & - & 0,5 & - & 0,39 & - & 0,67 & 0,53 & 0,56 & 0,45 & 1,42 & - & 0,57 & - & 0,46 & - & 0,7 \\
\hline C18:0 - Á. esteárico & 37,78 & 28,79 & 26,68 & 39,83 & 19,06 & 27,15 & 26,68 & 24,39 & 33,08 & 18,96 & 35,43 & 27,89 & - & 23,74 & 18,99 & 21,7 \\
\hline C18:1 - Á. oleico & 34,41 & 27,78 & 19 & 18,55 & 21,57 & 24,12 & 29,55 & 29,44 & 20,74 & 20,46 & 26,84 & 26,26 & - & 23,73 & 15,04 & 35,92 \\
\hline C18:2 - Á. linoleico & - & 2,74 & 2,52 & 1,73 & 10,34 & - & 1,91 & 2,16 & 1,29 & 1,39 & - & 2,36 & - & 1,37 & 0,98 & 2,55 \\
\hline $\begin{array}{l}\text { C18:3n3 - Á. } \\
\text { á-linolénico }\end{array}$ & - & 4,81 & 1,68 & - & 0,91 & 0,49 & 0,43 & 0,24 & - & - & - & - & - & 0,33 & 15,59 & 0,59 \\
\hline $\begin{array}{l}\text { C18:4 - Á. } \\
\text { octadecatetraenoico }\end{array}$ & - & 1,21 & 1,457 & 0,45 & 4,58 & 0,86 & 0,77 & - & 0,6 & 1,46 & - & 1,11 & - & 0,74 & 1,5 & 0,52 \\
\hline $\begin{array}{l}\text { C19:0 - Á. } \\
\text { nonadecanoico }\end{array}$ & - & 0,17 & - & - & - & 0,23 & 0,21 & - & - & - & - & - & - & 0,18 & - & 0,15 \\
\hline $\begin{array}{l}\text { C20:0 - Á. } \\
\text { araquídico }\end{array}$ & - & - & 0,86 & 0,28 & 1,47 & 0,48 & 0,34 & - & - & 0,36 & - & - & - & 0,33 & - & 0,25 \\
\hline $\begin{array}{l}\text { C20:1- Á. } \\
\text { eicosenoico }\end{array}$ & - & - & - & - & - & - & - & - & - & - & - & - & - & - & - & 0,46 \\
\hline $\begin{array}{l}\text { C20:2 - Á. } \\
\text { eicosadienoico }\end{array}$ & - & 5,07 & 8,8 & 2,88 & 5,44 & 3,24 & 4,67 & 3,01 & 2,47 & 1,44 & - & 5,67 & - & 8,05 & 3,75 & 1,41 \\
\hline $\begin{array}{l}\text { C21:1- Á. } \\
\text { heneicosenoico }\end{array}$ & - & & & & & 0,18 & 0,24 & - & - & - & - & - & - & 2 & - & - \\
\hline $\begin{array}{l}\text { C21:2 - } \\
\text { Á.heneicosadienoico }\end{array}$ & - & 0,45 & - & 8,55 & - & - & - & - & - & - & - & - & - & - & 23,89 & - \\
\hline $\begin{array}{l}\text { C22:2 - Á. } \\
\text { docosadienoico }\end{array}$ & - & 5,36 & 7,95 & 2,53 & 6,42 & - & 5,1 & - & - & - & - & 3,88 & - & 6,88 & - & - \\
\hline NN & - & 2,49 & 1,66 & 7,65 & 4,52 & 10,02 & 1,5 & 0,98 & 1,08 & 4,44 & - & 1,64 & - & 4,24 & 3,1 & 3,37 \\
\hline
\end{tabular}

Tabla 4. Resultados expresados en porcentaje de la composición de ácidos grasos de la muestra de grasa extraída de las piezas arqueológicas de LCH3 y de sedimentos de la Unidad 3. Referencias: Sed = sedimento. 


\section{De los grupos tardíos}

Del conjunto de materiales arqueológicos contenidos en la Unidad 4/5 de LCH1 fueron seleccionados 11 objetos para realizar análisis mediante cromatografía gaseosa (Tabla 5, Figura 4). El mismo análisis fue realizado sobre una muestra de sedimento, y el cromatograma resultante presentó escasos picos con áreas muy pequeñas. Esto significa que la muestra de grasa obtenida fue muy chica a pesar de que los porcentajes presentes en la tabla resulten altos. De esta forma, se descarta la posibilidad de que las muestras extraídas de los objetos arqueológicos sean resultado de la contaminación de los lípidos presentes en el sedimento. Los resultados obtenidos a partir de un molino de mano simple (35/1 2003) no se incluyen en la tabla porque estos resultados ya han sido publicados (Babot et al., 2007).

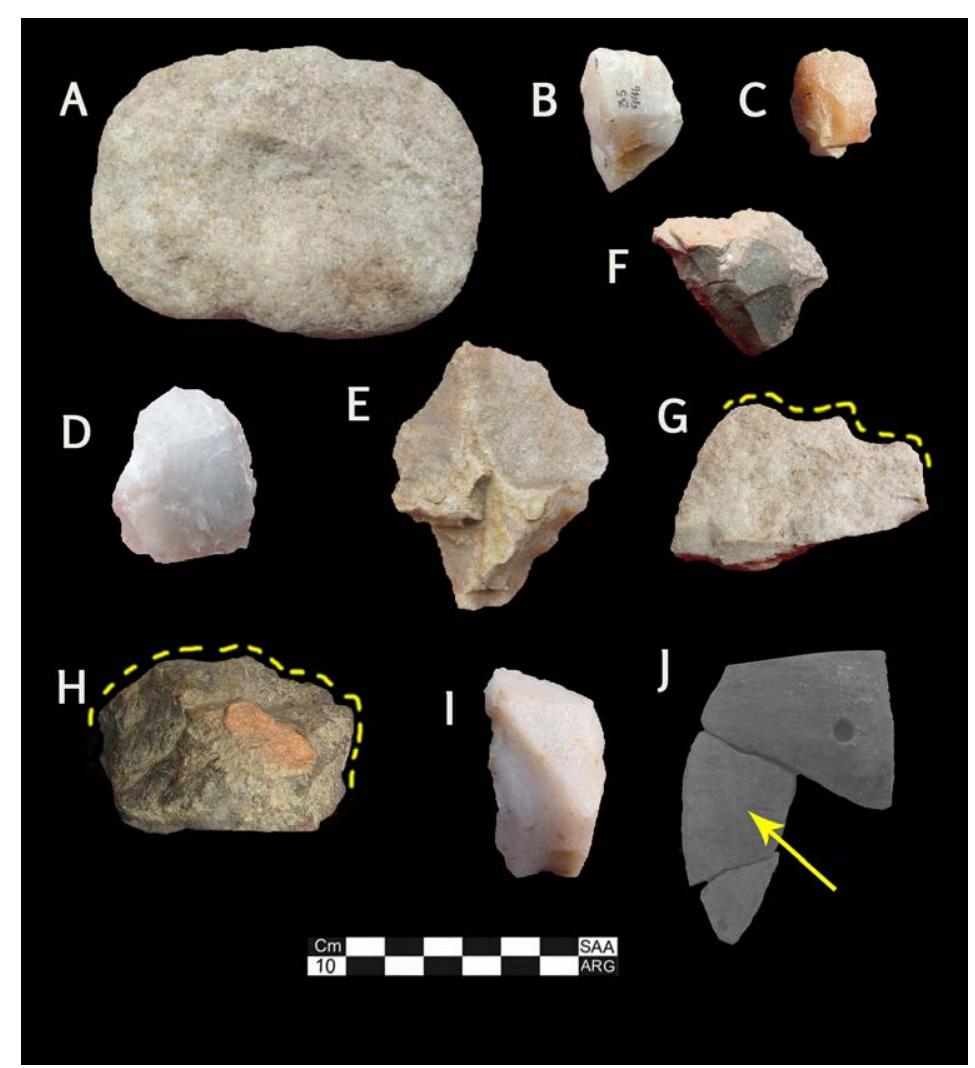

Figura 4. Artefactos líticos y cerámica provenientes de la Unidad 4/5 de LCH1. Referencias: A) $35 / 1$ 1664;B) 35/1 946;C) 35/1 1054;D) 35/1 1887; E) 35/1 1665; F) 35/1 363; G) 35/1 1985; H) 35/1 1174; I) 35/1 2001; J) 35/1 2118.

La muestra extraída del núcleo bipolar 35/1 946 no resultó suficiente para ser analizada, motivo por el cual el cromatograma resultante quedó en blanco. Esto pudo deberse a que este objeto no fue utilizado, a que las sustancias grasas no se hayan preservado o que haya sido utilizado sobre recursos inorgánicos, como por ejemplo otra roca.

La pieza 35/1 1664 es un instrumento compuesto que presenta un yunque sobre una de sus caras y un sobador sobre la otra. La extracción fue realizada únicamente de la cara identificada como sobador. El registro lipídico obtenido es abundante, aunque poco diagnóstico. Puede destacarse, sin embargo, la presencia de los ácidos grasos undecanoido, pentadecanoico, heptadecanoico y nonadecanoico como productos de la acción bacteriana sobre las sustancias (Buonasera, 2007; Robinson et al., 1991). Entre ellos, el ácido undecanoico es el menos frecuente en las bases de datos consultadas; 
en el conjunto de muestras experimentales sólo fue detectado en la muestra combinada de carne y vegetales (Mazzia, 2010-2011). Puede proponerse que este sobador ha sido utilizado en el pasado, aunque no puede precisarse el origen de los recursos procesados.

El registro lipídico 35/1 1054 es acotado, pero presenta una relación entre los porcentajes de los ácidos mirístico, palmítico, oleico y linoleico que resulta semejante a la descripta para la carne cruda de bagre (Frère et al., 2010). Esta comparación es sugerente, pero no concluyente debido al alto valor del ácido esteárico, el cual puede haber sido enriquecido a partir de la degradación de ácidos grasos más inestables como el linoleico, modificándose la relación original.

Se destaca el pequeño porcentaje con el que fue registrado el ácido linoleico en la muestra $35 / 11887$, por debajo del $1 \%$ con respecto al total. De acuerdo con las bases de datos conocidas no han sido detectados valores semejantes en vegetales (Robinson et al., 1991; United States Testing Company, Inc., 1955, tabla 9, pp. 28-29). Sin embargo, es posible que la baja representación se deba a la acción de procesos de degradación que provocaron su reducción, al tiempo que se incrementaba el ácido esteárico. A esto puede sumarse la identificación del ácido eicosadienoico con un $4,6 \%$ y del ácido docosadienoico con un $9 \%$. Estos ácidos grasos no se encuentran en animales terrestres conocidos (Frère et al., 2010; Robinson et al., 1991; United States Testing Company, Inc., 1955, tabla 9, pp. 28-29) y en animales acuáticos solo se registran valores muy pequeños, inferiores al 1\% (Brenner y Bernasconi, 1997). En cambio, en las muestras experimentales de origen vegetal se han obtenido valores comparables de estos dos ácidos grasos. Puede agregarse que el ácido graso C22:2 sólo fue identificado en las muestras con las que se procesó madera y vegetales. Se propone que esta raedera fue usada en el pasado y que su función estuvo destinada posiblemente al procesamiento de recursos de origen vegetal, incluida la madera.

El registro lipídico obtenido a partir de la muestra 35/1 1665 es abundante y diverso. Incluye una importante cantidad de ácidos grasos con número impar de átomos de carbono en su estructura molecular, identificados con la actividad bacteriana (Buonasera, 2007; Robinson et al., 1991). Entre ellos, los menos frecuentes en las bases de datos son los ácidos undecanoico y tridecanoico, ambos detectados en las muestras experimentales en las que se mezclaron recursos de origen animal y vegetal. Esto puede relacionarse con dos características de esta muestra: por un lado, al igual que en la muestra anterior, se registró un porcentaje de C22:2 que se acerca al 7\% y resulta comparable a los valores detectados en las piezas experimentales utilizadas para procesar madera y vegetales; en segundo lugar, la relación existente entre los porcentajes identificados de los ácidos mirístico, palmítico, esteárico, oleico y linoleico es similar a la relación descripta para grasas animales (Robinson et al., 1991; United States Testing Company, Inc., 1955, tabla 9, pp. 28-29). En este sentido, es posible que en esta raedera se hayan mezclado grasas de diferentes orígenes.

La muestra de grasa obtenida de 35/1 363 resultó abundante. Los ácidos grasos detectados incluyen a los ácidos mirístico, palmítico, esteárico, oleico y linoleico con porcentajes relativos que semejan aquellos descriptos para las grasas de origen animal (Robinson et al., 1991; United States Testing Company, Inc., 1955, tabla 9, pp. 28-29). En esta muestra también fueron registrados los ácidos grasos $\mathrm{C} 20: 2$ y C22:2, aunque en este caso se presentan en porcentajes menores. Se propone que este artefacto con retoques sumarios fue utilizado en el pasado sobre recursos de origen animal, pero no se descarta su contacto con vegetales, ya sea a causa de su uso para procesarlos o de su enmangue.

En el caso de la punta entre muescas $35 / 1$ 1985, su tamaño permitió sumergir en el solvente únicamente el filo formatizado. El cromatograma obtenido presenta una 
importante variedad de ácidos grasos. Los ácidos cáprico y araquídico tienen una distribución acotada en la naturaleza, pero en porcentajes inferiores al 1\% pueden hallarse tanto en grasas animales como en aceites vegetales (Babot et al., 2007; Buonasera, 2007). Se detectó un conjunto de ácidos grasos que comúnmente es relacionado con la síntesis bacteriana: C13:0, C15, C17, C19. Los porcentajes identificados para los ácidos mirístico, palmítico y oleico resultan comparables a aquellos registrados en la carne cruda de vizcacha (Frère et al., 2010). Sin embargo, la muestra arqueológica presenta una mayor cantidad de ácido esteárico y una menor cantidad en los ácidos linoleico y á-linolénico. Esta diferencia puede atribuirse al enriquecimiento del ácido esteárico debido a la degradación de los otros dos, más inestables. En suma, la utilización de este artefacto puede haber estado relacionada con el procesamiento de recursos animales.

La muestra 35/1 1174 fue extraída únicamente de los filos de este cepillo. El extracto obtenido fue abundante pero los resultados no permiten realizar interpretaciones inequívocas sobre el origen de las sustancias. Esto se debe a que el ácido esteárico fue registrado con $40,5 \%$. A pesar de que fueron identificados ácidos grasos de cadena larga/muy larga, tanto saturados como insaturados, que evidencian cierta estabilidad en la muestra a lo largo del tiempo, un valor tan elevado de ácido esteárico no es frecuente en la naturaleza y su enriquecimiento está relacionado con la degradación de otros ácidos grasos.

El extracto 35/1 2001 brindó un registro lipídico acotado en el que se registra nuevamente más del $40 \%$ de ácido esteárico. A esto debe sumarse que los picos identificados en el cromatograma tienen áreas pequeñas, lo que implica que la muestra de grasa que se obtuvo fue escasa.

Por último, se incluyó en el análisis un tiesto cerámico (35/1 2118) que ensambla con otros dos. Estos fragmentos de cerámica corresponden a un cuenco de borde directo con labio adelgazado (Mazzia y Flegenheimer, 2007). Para la extracción de la muestra fue posible sumergir en el solvente únicamente la parte interna del tiesto. El extracto lipídico fue uno de los más abundantes y diverso. Llama la atención la diferencia observada al comparar estos resultados con los descriptos para tiestos cerámicos provenientes de otros sitios arqueológicos. El registro lipídico de los materiales cerámicos de la localidad La Guillerma es muy acotado y presenta un alto porcentaje de ácido palmítico en relación con el ácido esteárico, interpretado como un posible uso de los recipientes para cocción de herbívoros terrestres de tamaño mediano (González y Frère, 2002). Una situación similar fue detectada en vasijas experimentales en las que se cocinó coipo y coipo mezclado con bagre (Frère et al., 2010). En el fragmento 35/1 2118 la relación entre ambos ácidos grasos es inversa, predominando el ácido esteárico por sobre el ácido palmítico, proporción identificada como evidencia de cocción de herbívoros de tamaño grande (Malainey, Przybylski y Sherriff, 1999). El resto de los compuestos identificados da cuenta de una importante actividad bacteriana sobre las sustancias y no es posible definir el origen de los lípidos de forma inequívoca. Es posible que este cuenco haya sido utilizado por quienes habitaron este abrigo rocoso para contener o elaborar alimentos de origen animal.

En el caso de $\mathrm{LCH} 2$, fueron seleccionados tres objetos líticos para este análisis (Figura 5). Sus resultados se detallan en la Tabla 6, junto a los resultados de una muestra de sedimentos de la Unidad 4 que los contenía. En este caso, la matriz brindó un conjunto de ácidos grasos abundante. Diferentes investigaciones explican que los objetos arqueológicos presentan una absorción mínima de sustancias de la matriz sedimentaria dada la naturaleza hidrofóbica de los lípidos, característica que limitaría su migración por disolución o difusión. De esta forma, los ácidos grasos provenientes del suelo pueden ser absorbidos en las porosidades de las rocas, pero 


\begin{tabular}{|c|c|c|c|c|c|c|c|c|c|c|c|}
\hline \multirow{2}{*}{ Ácido graso } & \multicolumn{11}{|c|}{ Muestra LCH1 - Unidad 4/5 } \\
\hline & Sed & 1664 & 946 & 1054 & 1887 & 1665 & 363 & 1985 & 1174 & 2001 & 2118 \\
\hline C10:0 - Á. cáprico & - & - & - & - & - & - & - & 0,04 & - & - & 0,08 \\
\hline C11:0 - Á. undecanoico & - & 0,13 & - & - & - & 0,24 & - & - & - & - & - \\
\hline C12:0 - Á. láurico & - & - & - & - & - & 0,35 & - & 0,15 & - & - & 0,38 \\
\hline C13:0 - Ácido tridecanoico & - & - & - & - & - & 0,18 & - & 0,23 & - & - & 0,31 \\
\hline C14:0 - Á. mirístico & - & 2,32 & - & 1,39 & 3,33 & 4,64 & 5,61 & 4,58 & 0,75 & - & 4,15 \\
\hline C14:1 - Á. miristoleico & - & 0,15 & - & - & - & 0,58 & 0,93 & 0,63 & 0,17 & - & - \\
\hline C15:0 - Á. pentadecanoico & - & 2,23 & - & - & 1,23 & 2,41 & 1,74 & 1,74 & 0,9 & - & 2,48 \\
\hline C16:0 - Á. palmítico & 12,54 & 23,48 & - & 20,72 & 19,45 & 17,57 & 20,43 & 23,77 & 13,67 & 14,14 & 22,43 \\
\hline C16:1 - Á. palmitoleico & - & 7,25 & - & 2,34 & 1,66 & 4,29 & 3,18 & 2,62 & 3,24 & 0,99 & 4,83 \\
\hline C17:0 - Á. heptadecanoico & 1,86 & 2,9 & - & 1,79 & 2,69 & 2,62 & 2,8 & 2,75 & 1,96 & 2,37 & 3,7 \\
\hline C17:1 - Á. heptadecenoico & - & - & - & - & 0,45 & 0,9 & 0,91 & 0,55 & - & - & - \\
\hline C18:0 - Á. esteárico & 56,37 & 24,35 & - & 38,66 & 31,09 & 23,39 & 24,57 & 27,46 & 40,47 & 40,43 & 32,15 \\
\hline C18:1 - Á. oleico & 24,35 & 22,67 & - & 31,74 & 25,29 & 19,8 & 27,91 & 23,29 & 22,91 & 38,96 & 14,22 \\
\hline C18:2 - Á. linoleico & 2,39 & 6,11 & - & 3,35 & 0,86 & 2,01 & 2,41 & 2,08 & 4,38 & 3,11 & 1,28 \\
\hline C18:3n3 - Á. á-linolénico & - & - & - & - & - & - & 0,2 & 0,28 & - & - & 0,68 \\
\hline C18:4 - Á. octadecatetraenoico & - & 1,67 & - & - & - & 1,84 & 0,52 & 0,7 & 1,25 & - & 1,06 \\
\hline C19:0 - Á. nonadecanoico & - & 0,37 & - & - & - & 0,22 & 0,21 & 0,21 & - & - & 0,55 \\
\hline C20:0 - Á. araquídico & 2,49 & 0,94 & - & - & - & 0,75 & 0,38 & 0,54 & 0,69 & - & 0,82 \\
\hline C20:2 - Á. eicosadienoico & - & 1,59 & - & - & 4,58 & 5,55 & 3,65 & 2,56 & 2,98 & - & 2,3 \\
\hline C21:1 - Á. heneicosenoico & - & - & - & - & - & 0,26 & - & - & - & - & - \\
\hline C21:2 - Á. heneicosadienoico & - & - & - & - & - & - & - & - & - & - & - \\
\hline C22:2 - Á. docosadienoico & - & - & - & - & 9,02 & 6,87 & 2,83 & - & 3,59 & - & 3,26 \\
\hline NN & - & 3,85 & - & - & 0,31 & 5,56 & 1,73 & 5,63 & 3,06 & - & 5,02 \\
\hline
\end{tabular}

Tabla 5. Resultados expresados en porcentaje de la composición de ácidos grasos de la muestra de grasa extraída de las piezas arqueológicas de LCH1 y de sedimentos de la Unidad 4/5. Referencias: Sed = sedimento.

tan lentamente que dichas sustancias se ven afectadas por procesos degradativos antes de acumularse en la muestra arqueológica en cantidades apreciables (Buonasera, 2007; Charters et al., 1993). Sin embargo, las inferencias que pueden realizarse a partir de las muestras arqueológicas resultan parciales ya que sólo serán considerados aquellos ácidos grasos ausentes en el sedimento o con valores considerablemente superiores. Las interpretaciones posibles se restringen aún más ya que a partir de la muestra $35 / 238$ se obtuvo un cromatograma en el que más del $26 \%$ del total de ácidos grasos no pudieron ser determinados. Por lo tanto, las relaciones existentes entre los valores de los ácidos grasos que sí fueron identificados no resultan confiables para inferir el origen de las sustancias. Los otros dos extractos provienen de dos objetos clasificados como núcleos bipolares. En el 35/2 35 el único ácido graso que puede ser considerado para ser relacionado con un origen concreto (y por no estar presente en el sedimento) es el C22:2. Este ácido graso fue registrado en la composición grasa de las muestras experimentales cuyo origen es vegetal exclusivamente. Algo similar ocurre con la muestra $35 / 225$. Nuevamente, la información utilizada como referencia proviene de las muestras experimentales debido a que no pudieron encontrarse datos comparables en las fuentes bibliográficas. Se registraron los ácidos heneicosenoico, heneicosadienoico y docosadienoico, ausentes en el sedimento. A esto puede sumarse el dato del ácido eicosadienoico que fue identificado en la matriz sedimentaria, pero en una proporción menor. Todos estos ácidos grasos y las proporciones en las que fueron registrados pueden ser interpretados como indicios de la presencia de aceites vegetales. 


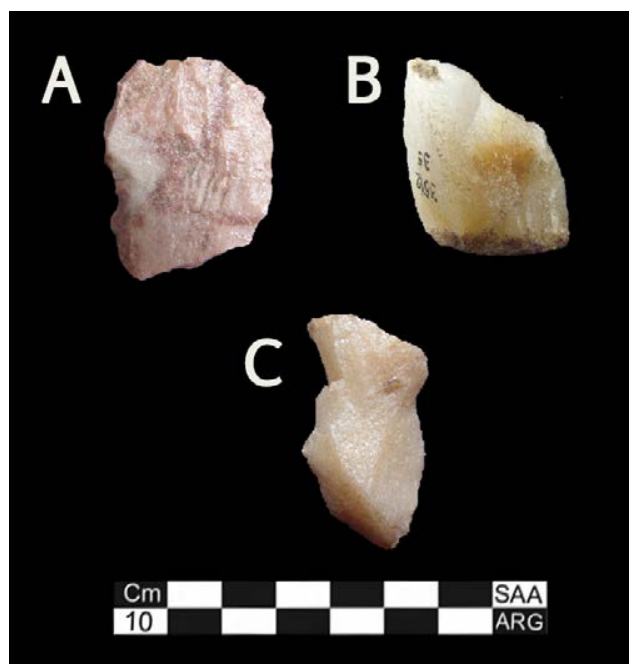

Figura 5. Artefactos líticos provenientes de la Unidad 4 de LCH2. Referencias: A) $35 / 238$; B) $35 / 235$; C) 35/2 25.

\begin{tabular}{|l|c|c|c|c|}
\hline \multirow{2}{*}{ Ácido graso } & \multicolumn{4}{|c|}{ Muestra LCH2 - Unidad 4 } \\
\cline { 2 - 5 } & Sed & $\mathbf{3 8}$ & $\mathbf{3 5}$ & $\mathbf{2 5}$ \\
\hline C12:0 - Á. láurico & 0,29 & - & - & - \\
C14:0 - Á. mirístico & 1,06 & 0,4 & 3,53 & 3,92 \\
C14:1 - Á. miristoleico & - & - & 0,39 & 0,49 \\
C15:0 - Á. pentadecanoico & 1,66 & 0,23 & 1,4 & 1,31 \\
C16:0 - Á. palmítico & 18,01 & 9,76 & 21,23 & 17,94 \\
C16:1 - Á. palmitoleico & 1,9 & 1,23 & 2,95 & 2,79 \\
C17:0 - Á. heptadecanoico & 2,11 & 1,19 & 2,47 & 2,08 \\
C17:1 - Á. heptadecenoico & - & 0,44 & 0,59 & 0,6 \\
C18:0 - Á. esteárico & 32,39 & 16,34 & 25,16 & 20,15 \\
C18:1 - Á. oleico & 28,95 & 17,12 & 24,39 & 24,79 \\
C18:2 - Á. linoleico & 3,56 & 1,17 & 2,12 & 2,04 \\
C18:3n3 - Á. á-linolénico & - & - & - & 0,18 \\
C18:4 - Á. octadecatetraenoico & 2,75 & - & 0,7 & 0,71 \\
C19:0 - Á. nonadecanoico & - & - & - & 0,17 \\
C20:0 - Á. araquídico & 1,36 & - & 0,35 & 0,29 \\
C20:2 - Á. eicosadienoico & 4,39 & 7,46 & 5,01 & 9,59 \\
C21:1 - Á. heneicosenoico & - & - & - & 1,87 \\
C21:2 - Á. heneicosadienoico & - & 12,22 & - & 0,55 \\
C22:2 - Á. docosadienoico & - & 6,2 & 8,46 & 9,16 \\
NN & 1,56 & 26,25 & 1,24 & 1,43 \\
\hline
\end{tabular}

Tabla 6. Resultados expresados en porcentaje de la composición de ácidos grasos de la muestra de grasa extraída de las piezas arqueológicas de LCH2 y de sedimentos de la Unidad 4. Referencias: Sed = sedimento.

Del contexto asignado a los grupos que visitaron LCH3 durante el Holoceno tardío fueron muestreados cinco instrumentos (Figura 6). Los extractos obtenidos se detallan en la Tabla 7 junto a los resultados obtenidos a partir del análisis realizado sobre una muestra de los sedimentos de la Unidad 4. Al igual que en $\mathrm{LCH} 2$, la matriz sedimentaria presentó un registro lipídico diverso. La comparación de la composición de las muestras arqueológicas con la muestra proveniente de los sedimentos podría generar dudas 
acerca de la confiabilidad de las inferencias sobre los usos en el pasado de estos objetos. Por este motivo, las muestras arqueológicas obtenidas no serán consideradas para realizar interpretaciones sobre el posible origen de las sustancias detectadas.

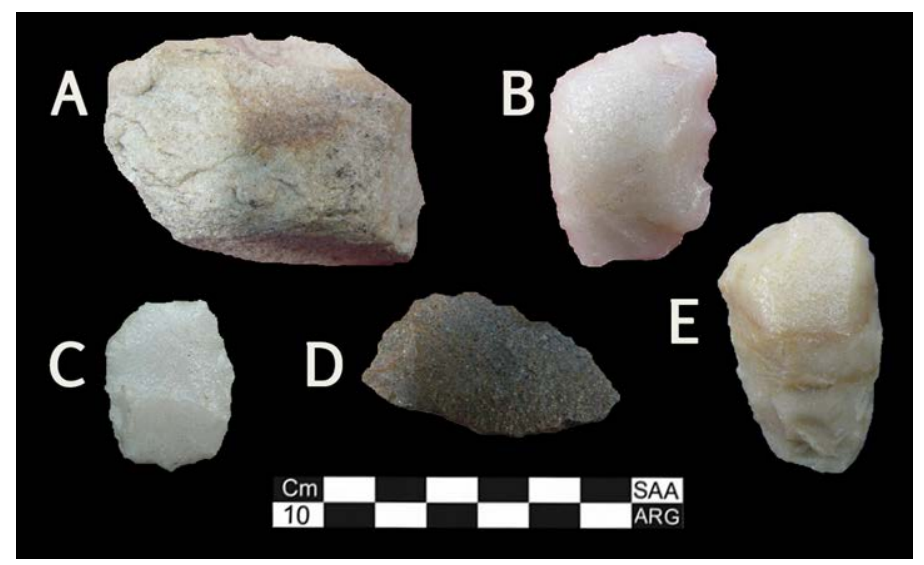

Figura 6. Artefactos líticos provenientes de la Unidad 4 de LCH3. Referencias: A) $35 / 3$ 1491; B) 35/3 758; C) 35/3 1863; D) 35/3 1516; E) 35/3 14.

Cabe destacar que la pieza 35/3 1516 no brindó una muestra de grasa suficiente para ser detectada por el cromatógrafo gaseoso y el cromatograma resultante quedó en blanco. La ausencia de materia grasa en su superficie llama la atención teniendo en cuenta la posibilidad de contaminación por los sedimentos propuesta anteriormente. A partir de las cuatro piezas restantes ( $35 / 3$ 1491, 35/3 758, 35/3 1863, 35/3 14) se obtuvieron muestras lipídicas con composiciones heterogéneas, otro aspecto que resulta importante al considerar que, si existió una contaminación post descarte, ésta no actuó de la misma manera sobre los diferentes objetos.

\section{Discusión}

Como resultado del análisis químico realizado sobre una muestra de 13 artefactos líticos asignados a la ocupación temprana de $\mathrm{LCH} 1$, fue posible establecer que al menos siete de ellos fueron usados en el pasado. En seis de los instrumentos se encontró una mezcla de recursos vegetales y animales, dos de los cuales incluirían la posibilidad de enmangue. En tanto, solamente un artefacto fue usado en forma exclusiva para el procesamiento de recursos animales terrestres. En el caso del contexto temprano de la LCH3, 14 de los 15 artefactos líticos muestreados fueron utilizados sobre recursos orgánicos por los habitantes de este espacio. Los recursos procesados fueron tanto vegetales como animales. Sin embargo, es necesario subrayar la identificación de aceites de semillas en dos de estos objetos y de grasas de animales de vida acuática en tres.

En lo que respecta al Holoceno tardío, fueron analizados 11 objetos arqueológicos de la Unidad $4 / 5$ de $\mathrm{LCH} 1$, y ocho de ellos presentaron evidencias de haber sido utilizados en el pasado sobre recursos orgánicos. No se observó en los resultados el predominio de algún tipo de recurso: se identificaron tanto grasas de animales terrestres, de aceites vegetales, como mezcla de ambos. A partir de los artefactos muestreados de $\mathrm{LCH} 2 \mathrm{y}$ LCH3 no pudo obtenerse información que diera cuenta de los recursos orgánicos con los que estuvieron en contacto directo, dado que el registro lipídico presente en las muestras de sedimentos resultó en ambos casos diverso y abundante. En el caso de $\mathrm{LCH} 2$, las dos piezas a partir de las cuales se pudo interpretar parcialmente el origen de las sustancias indicaron su utilización sobre recursos vegetales. 


\begin{tabular}{|l|c|c|c|c|c|c|}
\hline \multirow{2}{*}{ Ácido graso } & \multicolumn{5}{|c|}{ Muestra LCH3 - Unidad 4 } \\
\cline { 2 - 7 } & Sed & $\mathbf{1 4 9 1}$ & $\mathbf{7 5 8}$ & $\mathbf{1 8 6 3}$ & $\mathbf{1 5 1 6}$ & $\mathbf{1 4}$ \\
\hline C10:0 - Á. cáprico & 0,15 & - & - & - & - & - \\
C11:0 - Á. undecanoico & - & 0,09 & - & - & - & - \\
C13:0 - Á. láurico & 1,48 & 0,19 & - & - & - & - \\
C14:0 - Á. mirístico & 1,96 & 0,22 & - & - & - & - \\
C14:1 - Á. miristoleico & 4,17 & 10,83 & 2,10 & 0,36 & - & 2,22 \\
C15:0 - Á. pentadecanoico & - & 1,57 & - & - & - & 0,26 \\
C16:0 - Á. palmítico & 3,56 & 3,63 & 0,71 & - & - & 1,75 \\
C16:1 - Á. palmitoleico & 20,8 & 20,78 & 24,56 & 15,81 & - & 26,21 \\
C17:0 - Á. heptadecanoico & 3,75 & 3,94 & 2,24 & 1,02 & - & 2,85 \\
C17:1 - Á. heptadecenoico & 3,01 & 2,67 & 2,79 & 2,37 & - & 3,19 \\
C18:0 - Á. esteárico & 1,19 & 0,88 & - & - & - & 0,65 \\
C18:1 - Á. oleico & 21,14 & 19,94 & 37,38 & 41,11 & - & 31,06 \\
C18:2 - Á. linoleico & 17,57 & 20,89 & 26,08 & 36,62 & - & 21,35 \\
C18:3n3 - Á. á-linolénico & 1,59 & 2,6 & 2,63 & 2,7 & - & 2,42 \\
C18:4 - Á. octadecatetraenoico & 0,59 & - & - & - & - & - \\
C20:0 - Á. araquídico & 1,34 & 0,73 & - & - & - & 2,11 \\
C20:2 - Á. eicosadienoico & 2,94 & 0,33 & - & - & - & 1,17 \\
C22:2 - Á. docosadienoico & 4,93 & 2,48 & - & - & - & 3,15 \\
NN & 3,89 & 2,73 & - & - & - & - \\
\hline
\end{tabular}

Tabla 7. Resultados expresados en porcentaje de la composición de ácidos grasos de la muestra de grasa extraída de las piezas arqueológicas de $\mathrm{LCH} 3$ y de sedimentos de la Unidad 4. Referencias: Sed = sedimento.

A partir de muestreos en otros sitios de la microrregión serrana hemos realizado los mismos análisis. En Cueva Zoro (Figura 1C), en un contexto de una ocupación efímera asignada a fines del Pleistoceno se analizaron 13 objetos líticos (Mazzia, 2013). Del conjunto recuperado en Cerro El Sombrero Cima (CoS Cima; Figura 1B) se analizaron 39 objetos líticos y se encontraron resultados comparables a los de la ocupación temprana de LCH3 (Flegenheimer, Weitzel y Mazzia, 2015; Mazzia y Flegenheimer, 2015). En El Ajarafe (Figura 1D), un abrigo en la cima de Sierra Larga sur con ocupaciones humanas efímeras tanto en el Holoceno temprano como en el tardío, se registraron recursos orgánicos en siete artefactos (Mazzia, 2011). Considerados en conjunto, los datos obtenidos hasta el momento para todos estos sitios ofrecen la posibilidad de reflexionar sobre el uso de ciertos recursos orgánicos en el pasado que anteriormente no habían sido considerados. Por ejemplo, pudieron detectarse composiciones lipídicas compatibles con aceites de semillas ( $\mathrm{LCH} 3$, Unidad 3 y CoS Cima), con grasas animales acuáticas, lo que incluye la posibilidad de que se trate de recursos marinos ( $\mathrm{LCH} 3$, Unidad 3; CoS Cima; El Ajarafe, ocupación temprana; Cueva Zoro) y con la existencia de un enmangue de origen vegetal ( $\mathrm{LCH} 1$, Unidad 3 y Unidad 4/5; CoS Cima; El Ajarafe, ocupación tardía; Cueva Zoro). Es cierto que aún no resulta posible definir un origen más preciso de cada uno de estos compuestos que permita inferir el tipo de vegetal o de animal involucrado. Si bien esta metodología de análisis ya cuenta con una importante trayectoria de aplicación en la arqueología argentina ( $p$. ej. Babot, 2004; Babot et al., 2007; Bonomo, Colobig y Mazzia, 2012; Costa Angrizani y Constenla, 2010; Fiore, Maier, Parera, Orquera y Piana, 2008; Frère, González, Chan y Flores, 2016; Gómez Otero, Constenla y Schuster, 2014; González y Frère, 2002; Mazzia 2010-2011; Naranjo, Malec y Pérez, 2010; Stoessel, Martínez y Constenla, 2015), los resultados alcanzados no son concluyentes, debido a la necesidad de contar con una 
base de datos de referencia completa sobre los recursos disponibles en el pasado y sobre la forma en la que las sustancias son degradadas sobre los objetos.

No obstante, es destacable que la información obtenida a partir del análisis de las sustancias grasas nos da indicios importantes sobre el uso y la versatilidad de los diferentes tipos de instrumentos, de la variedad de recursos orgánicos utilizados e, incluso, de los recorridos y distancias implicados para buscarlos. La circulación de personas y objetos a través del espacio pampeano ha sido ampliamente discutida a partir de las fuentes de abastecimiento de las materias primas líticas, principalmente de las CGSB (p. ej. Bayón y Flegenheimer, 2004; Bayón, Flegenheimer y Pupio, 2006; Colombo, 2013; Flegenheimer, Kain, Zárate y Barna, 1996; Franco, 1994). Para quienes habitaron los lugares de LCH, la obtención de las CGSB implicó recorridos de $80 \mathrm{~km}$ hacia el noroeste. En ese mismo trayecto a menor distancia, unos $35 \mathrm{~km}$, disponían de fuentes de dolomía silicificada (Flegenheimer, 1991). Para abastecerse de ftanita pudieron hacerlo en la misma área que la CGSB o debieron recorrer distancias mayores, $180 \mathrm{~km}$ aproximadamente, también en dirección noroeste (Barros y Messineo, 2004). La caliza silicificada, utilizada en los contextos tempranos de LCH1 y LCH3, amplía las distancias por las que circularon objetos, personas e información, dado que sus afloramientos se localizan a más de $400 \mathrm{~km}$ hacia el noreste (Flegenheimer et al., 2003). Junto a estos recorridos ya conocidos y discutidos, podemos considerar que quienes habitaron esta microrregión serrana incluyeron en sus trayectos visitas a la costa atlántica. Durante fines del Pleistoceno la línea de costa habría estado a más de 120 $\mathrm{km}$ de distancia hacia el este (Parker et al., 2008; Ponce, Rabassa, Coronato y Borromei, 2011). Los datos obtenidos sobre el procesamiento de recursos marinos a partir de los análisis cromatográficos se suman a otras evidencias en el mismo sentido como, por ejemplo, el registro de consumo de animales marinos en individuos inhumados en Arroyo Seco 2 durante el Holoceno temprano-medio a partir de estudios de isótopos estables (Scabuzzo, 2010) o la identificación de artefactos de basalto, posiblemente de la costa atlántica (Martínez y Gutiérrez, 2011). Es decir, al igual que las fuentes de abastecimiento de CGSB, la costa atlántica representa un nodo más en el entramado espacial habitual de los cazadores-recolectores pampeanos.

\section{Palabras finales}

La metodología de análisis utilizada en este trabajo representa una herramienta de suma importancia y lo es aún más en contextos como los de LCH, en los que existe una escasa o nula preservación de macrorrestos orgánicos. Los análisis cromatográficos nos han permitido obtener mayor información a partir de la materialidad disponible. Resulta destacable la preservación de las sustancias grasas obtenidas a partir de artefactos utilizados hace más de 10.000 años, incluso en objetos que fueron lavados y conservados en depósito durante 25 años. Entre los datos obtenidos, se destacan el registro de sustancias grasas en artefactos clasificados como núcleos bipolares que dan cuenta de su utilización sobre recursos orgánicos y la evidencia del procesamiento de semillas y de animales marinos. La identificación del uso de la cerámica para contener o elaborar alimentos de origen animal terrestre resulta relevante para sumar a las bases de datos de ácidos grasos provenientes de vasijas cerámicas arqueológicas y experimentales, ya existentes en región pampeana. Además, en las distintas ocupaciones de los tres espacios de LCH hay un registro equilibrado entre los recursos vegetales y animales; es notable la gran cantidad de artefactos que presentaron una mezcla de sustancias de origen animal y vegetal, indicando la versatilidad de los artefactos.

Poder aproximarnos a los diferentes tipos de recursos orgánicos utilizados nos abre nuevas posibilidades para complementar las diferentes vías de análisis con las que 
abordamos las múltiples aristas de la vida en el pasado, entre ellas los usos de los artefactos en las actividades cotidianas y los movimientos de las personas y sus objetos en el entorno pampeano.

\section{Agradecimientos}

Los análisis cromatográficos fueron posibles gracias a la empresa Materia Hnos. y la buena predisposición de su personal. El material analizado es el resultado del trabajo de muchos años en el que han colaborado muchos colegas. Martín Barbería, de la estancia Santa María, quien nos abrió la tranquera para la revisita a los sitios. Valeria Lukezic colaboró con la confección de las figuras. Dos evaluadores/ras enriquecieron la versión original con sus sugerencias. A todos y todas, muchas gracias. 


\section{Referencias citadas}

» Babot, M. del P. (2004). Tecnología y utilización de artefactos de molienda en el Noroeste Prehispánico. (Tesis Doctoral inédita), Universidad Nacional de Tucumán, Argentina.

» Babot, M. P., Mazzia, N. y Bayón, C. (2007). Procesamiento de recursos en la región pampeana bonaerense: aportes del instrumental de molienda de las localidades arqueológicas El Guanaco y Cerro La China. En C. Bayón, A. Pupio, M. I. González, N. Flegenheimer y M. Frère (Eds.), Arqueología en las pampas (pp. 635-660). Bahía Blanca: Sociedad Argentina de Antropología.

» Baeten, J., Jervis, B., De Vos, D. y Waelkens, M. (2013). Molecular evidence for the mixing of Meat, fish and vegetables in Anglo- Saxon coarseware from Hamwic, UK. Archaeometry, 55, 1150-1174. https://doi.org/10.1111/j.1475-4754.2012.00731.x

» Barba, L., Ortiz, A. y Pecci, A. (2014). Los residuos químicos. Indicadores arqueológicos para entender la producción, preparación, consumo y almacenamiento de alimentos en Mesoamérica. Anales de Antropología, 48(1), 201-239. http://dx.doi.org/10.1016/S01851225(14)70495-3

»Barros, P. y Messineo, P. (2004). Identificación y aprovisionamiento de ftanita o chert en la cuenca superior del Ao. Tapalqué (Olavarría, Pcia. de Bs. As., Argentina). Estudios Atacameños, 28, 87-103. http://dx.doi.org/10.4067/S0718-10432004002800008

» Bayón, C. y Flegenheimer, N. (2004). Cambio de planes a través del tiempo para el traslado de roca en la pampa bonaerense. Estudios Atacameños, 28, 59-70. http://dx.doi.org/10.4067/ s0718-10432004002800006

» Bayón, C., Flegenheimer, N. y Pupio, A. (2006). Planes sociales en el abastecimiento y traslado de roca en la pampa bonaerense en el Holoceno temprano y tardío. Relaciones de la Sociedad Argentina de Antropología, XXXI, 19-45. http://www.saantropologia.com.ar/textos/planessociales-en-el-abastecimiento-y-traslado-de-roca-en-la-pampa-bonaerense-en-el-holocenotemprano-y-tardio/.

» Bondia Pons, I. (2007). Estudio del perfil de ácidos grasos en la evaluación de la dieta mediterránea como patrón de dieta saludable en poblaciones europeas. (Tesis Doctoral inédita), Universidad de Barcelona, España. https://www.tesisenred.net/ handle/10803/2434

» Bonomo, M., Colobig, M. y Mazzia, N. (2012). Análisis de residuos orgánicos y microfósiles silíceos de la 'cuchara' de cerámica del sitio arqueológico Cerro Tapera Vázquez (Parque Nacional Pre-Delta, Argentina). Revista do Museu de Arqueologia e Etnologia, 22, 31-50. http:// sedici.unlp.edu.ar/handle/10915/109301

»Brenner, R. R. y. Bernasconi, A. M. (1997). Aporte de ácidos grasos esenciales de las series n-6 y n-3 a la dieta humana por pescados comestibles del Río Paraná. Medicina, 57, 307314.

» Buonasera, T. (2007). Investigating the presence of ancient absorbed organic residues in groundstone using GCeMS and other analytical techniques: a residue study of several prehistoric milling tools from central California. Journal of Archaeological Science, 34, 13791390. https://doi.org/10.1016/j.jas.2006.10.028

» Charters, S., Evershead, R. P., Goad, L. J., Leyden, A., Blinkhorn, P. W. y Denham, V. (1993). Quantification and distribution of lipid in archaeological ceramics: implications for sampling potsherds for organic residue analysis and the classification of vessel use. Archeometry, 35(2), 211-223. https://doi.org/10.1111/j.1475-4754.1993.tb01036.x

»Colombo, M. (2013). Los cazadores recolectores pampeanos y sus rocas. La obtención de materias primas líticas vista desde las canteras arqueológicas del centro de Tandilia. (Tesis Doctoral inédita), Universidad Nacional de La Plata, Argentina. http://sedici.unlp.edu.ar/ handle/10915/29170 
» Costa Angrizani, R. y Constenla, D. (2010). Sobre yapepós, ñaembés y cambuchís: aproximaciones a la funcionalidad de vasijas cerámicas a partir de la determinación de ácidos grasos residuales en tiestos recuperados en contextos arqueológicos en el sur de Brasil. En M. Berón, L. Luna, M. Bonomo, C. Montalvo, C. Aranda y M. Carrera Aizpitarte (Eds.), Mamül Mapu: pasado y presente desde la arqueología pampeana (pp. 215-224). Buenos Aires: Editorial Libros del Espinillo.

»Evershed, R. P. (2008). Organic residue analysis in archaeology: The archaeological biomarker revolution. Archaeometry, 50(6), 895-924. https://doi.org/10.1111/j.14754754.2008.00446.x

» Evershed, R. P., Heron, C., Charters, S. y Goad, L. J. (1992). Chemical analysis of organic residues in ancient pottery: methodological guidelines and applications. En R. White y $\mathrm{H}$. Page (Eds.), Organic residues in archaeology: their identification and analysis (pp. 11-24). York: United Kingdom Institute for Conservation, Archaeology Section.

» Fiore, D., Maier, M., Parera, S. D., Orquera, L. y Piana, E. (2008). Chemical analyses of the earliest pigment residues from the uttermost part of the planet (Beagle Channel region, Tierra del Fuego, Southern South America). Journal of Archaeological Science, 35, 3047-3056. https://doi.org/10.1016/j.jas.2008.04.003

" Flegenheimer, N. (1980). Hallazgos de puntas "cola de pescado" en la Provincia de Buenos Aires. Relaciones de la Sociedad Argentina de Antropología, XIV(1), 169-175. http://www. saantropologia.com.ar/textos/puntas-cola-de-pescado-en-la-provincia-de-buenos-aires/

»Flegenheimer, N. (1986-1987). Excavaciones en el Sitio 3 de la Localidad Cerro La China (Pcia. de Bs. As.). Relaciones de la Sociedad Argentina de Antropología, XVII(1), 7-28. http:// www.saantropologia.com.ar/textos/excavaciones-en-el-sitio-3-cerro-la-china-provincia-debuenos-aires/.

» Flegenheimer, N. (1991). La Liebre, un sitio de cantera-taller. Boletín del Centro, 2, 58-64.

»Flegenheimer, N. (2004). Las ocupaciones de la transición Pleistoceno-Holoceno: una visión sobre las investigaciones en los últimos 20 años en la Región pampeana. Trabajo presentado en Actas del X Congreso Nacional de Arqueología Uruguaya, [CD ROM]. Uruguay.

» Flegenheimer, N., Bayón, C., Valente, M., Baeza, J. y Femenías, J. (2003). Long distance tool stone transport in Argentine Pampas. Quaternary International, 109-110, 49-64. https://doi. org/10.1016/S1040-6182(02)00202-1

» Flegenheimer, N., Kain, S., Zárate, M. y Barna, A. (1996). Aprovisionamiento de rocas cuarcíticas en Tandilia. Las canteras del Arroyo Diamante. Arqueología, 6, 117-143.

"Flegenheimer, N., Mazzia, N. y Weitzel, C. (2015). Landscape and rocks in the central-east portion of the Tandilia range (Buenos Aires province, Argentina). Paleoamerica, 1(2), 163-180. https://doi.org/10.1179/2055556315Z.00000000017

» Flegenheimer, N., Weitzel, C. y Mazzia, N. (2015). Miniature points in an exceptional early South American context. Word Archaeology, 47(1), 117-136. http://dx.doi.org/10.1080/004382 43.2014.991806

» Frère, M. M., Constenla, D., Bayón, C. y González, M. I. (2010). Estudios actualísticos sobre recursos silvestres mediante el empleo de análisis químicos. En M. Berón, L. Luna, M. Bonomo, C. Montalvo, C. Aranda y M. Carrera Aizpitarte (Eds.), Mamül Mapu: pasado y presente desde la arqueología pampeana (pp. 65-76). Buenos Aires: Editorial Libros del Espinillo.

» Frère, M. M., González, M. I., Chan, D. y Flores, M. (2016). Evidencias químicas de preparación de alimentos en la alfarería de la depresión del río Salado. Anuario de Arqueología, Rosario, 8, 141-151. http://hdl.handle.net/2133/6557

»Franco, N. (1994). Maximización en el aprovechamiento de los recursos líticos. Un caso analizado en el Área Interserrana Bonaerense. En J. L. Lanata y L. A. Borrero (Eds.), Arqueología de Cazadores-Recolectores. Límites, Casos y Aperturas (pp. 75-88). Buenos Aires: Arqueología Contemporánea 5, Edición especial. 
»Gómez Otero, J., Constenla, D. y Schuster, V. (2014). Análisis de isótopos estables de carbono y nitrógeno y cromatografía gaseosa en cerámica arqueológica del nordeste de la provincia de Chubut (Patagonia Argentina). Arqueología, 20(2), 263-284. https://doi.org/10.34096/ arqueologia.t20.n2.1640

»González, M. I. y Frère, M. M. (2002). Explorando algunos usos prehispánicos de la alfarería pampeana. En D. Mazzanti, M. Berón y F. Oliva (Eds.), Del Mar a los Salitrales. Diez Mil Años de Historia Pampeana en el umbral del Tercer Milenio (pp. 31-40). Mar del Plata: Facultad de Humanidades, Universidad Nacional de Mar del Plata, Sociedad Argentina de Antropología.

»Leipus, M. (2002). Análisis Funcional de instrumentos líticos de los sitios Cerro La China y Cerro El Sombrero, provincia de Buenos Aires: resultados preliminares y perspectivas. Informe presentado a N. Flegenheimer. Manuscrito inédito.

» Malainey, M. E. (2007). Fatty acid analysis of archaeological residues: procedures and possibilities. En H. Barnard y J. W. Eerkens (Eds.), Theory and practice of archaeological residues analysis (pp. 77-89). Oxford: BAR International Series 1650, Archaeopress.

» Malainey, M. E., Przybylski, R. y Sherriff, B. L. (1999). The Fatty Acid Composition of Native Food Plants and Animals of Western Canada. Journal of Archaeological Science, 26 (1), 83-94. https://doi.org/10.1006/jasc.1998.0305

» Martínez, G. y Gutiérrez, M. (2011). Paso Otero 5: a summary of the Interdisciplinary lines of evidence for reconstructing early human occupation and paleoenvironment in the Pampean Region, Argentina. En D. Vialou (Ed.), Peuplements et Préhistoire en Ameriques (pp. 271-284). Francia: Museum National d'Histoire Naturelle.

» Mazzia, N. (2010-2011). Lugares y paisajes de cazadores recolectores en la Pampa bonaerense: cambios y continuidades durante el Pleistoceno final - Holoceno. (Tesis Doctoral inédita), Universidad Nacional de La Plata, Argentina. http://sedici.unlp.edu.ar/ handle/10915/83432

» Mazzia, N. (2011). El Ajarafe: Un espacio serrano ocupado efímeramente en diferentes momentos del Holoceno (Tandilia, Provincia de Buenos Aires). Revista del Museo de Antropología, 4(1), 33-46. https://doi.org/10.31048/1852.4826.v4.n1.5481

» Mazzia, N. (2013). Cueva Zoro: nuevas evidencias sobre pobladores tempranos en el sector centro oriental de Tandilia. Intersecciones en Antropología, 14, 93-106. http://www.ridaa. unicen.edu.ar/xmlui/handle/123456789/1213

» Mazzia, N., Brardinelli, J. y Roncaglia, D. (2017). Recorrido hacia una nueva técnica de análisis de sustancias grasas sobre artefactos líticos tallados. En A. M. Rocchietti, F. Ribero y D. Reinoso (Eds.), Investigaciones arqueométricas: técnicas y procesos (pp. 147-161). Buenos Aires: Aspha Ediciones.

» Mazzia, N. y Flegenheimer, N. (2007). Retorno a La China: una visión de las ocupaciones tardías. En C. Bayón, N. Flegenheimer, M. I. González, M. Frère y A. Pupio (Eds.), Arqueología en las pampas (pp. 549-566). Bahía Blanca: Departamento de Humanidades, Universidad Nacional del Sur.

» Mazzia, N. y Flegenheimer, N. (2015). Detailed fatty acids analysis on lithic tools, Cerro El Sombrero Cima, Argentina, Quaternary International, 363, 94-106. https://doi.org/10.1016/j. quaint.2014.04.027

» Mazzia, N., Flegenheimer, N. y Poiré, D. (2005). Not only flaked artifacts in early Pampean lithic assemblages (Argentina). Current Research in the Pleistocene, 22, 25-28.

» Muhamad, N.A. y Mohamad, J. (2012). Fatty acids composition of selected Malaysian fishes. Sains Malaysiana, 41(1), 81-94.

» Naranjo, G., Malec, L. y Pérez, M. (2010). Análisis de ácidos grasos en alfarería arqueológica del humedal del Paraná inferior. Avances en el conocimiento de su uso. En J. R. Bárcena y H. Chiavazza (Eds.), Arqueología Argentina en el Bicentenario de la Revolución de Mayo (pp. 1493-1498). Mendoza: Facultad de Filosofía y Letras, Universidad Nacional de Cuyo. 
»Parker, G., Violante, R. A., Paterlini, C. M., Costa, I., Marcolini, S. y Cavallotto, J. (2008). Las secuencias depositacionales del Plioceno-Cuaternario en la plataforma submarina adyacente al litoral del este bonaerense. Latin American Journal of Sedimentology and Basin Analysis, 15(2), 105-124. https://www.redalyc.org/articulo.oa?id=381740362003

» Patrick, M., de Koning, A. J. y Smith, A. B. (1985). Gas liquid chromatographic analysis of fatty acids in food residues from ceramics found in the Southwestern cape, South Africa. Archeometry, 27(2), 231-236. https://doi.org/10.1111/j.1475-4754.1985.tb00366.x

»Pecci, A., Barba, L. y Ortiz, A. (2017). Chemical Residues as Anthropic Activity Markers. Ethnoarchaeology, Experimental Archaeology and Archaeology of Food Production and Consumption. Environmental Archaeology, 22(4), 343-353. https://doi.or $\mathrm{g} / 10.1080 / 14614103.2017 .1359354$

» Ponce, F., Rabassa, J., Coronato, A. y Borromei, A. M. (2011). Palaeogeographical evolution of the Atlantic coast of Pampa and Patagonia from the last glacial maximum to the Middle Holocene. Biological Journal of the Linnean Society, 103(2), 363-379. https://doi.org/10.1111/ j.1095-8312.2011.01653.x

» Robinson, D., Calvo Rebollar, M. y Sevillano Calvo, E. (1991). Bioquímica y valor nutritivo de los alimentos. España: Editorial Acribia.

» Rottländer, R. C. A. (1990). Lipid analysis in the identification of vessel contents. MASCA Research papers in Science and Archaeology, 7, 37-40.

»Scabuzzo, C. (2010). Actividades, patologías y nutrición de los cazadores recolectores pampeanos. (Tesis Doctoral inédita), Universidad Nacional de La Plata, Argentina. http:// sedici.unlp.edu.ar/handle/10915/35298

»Sengör, F., Özden, Ö., Erkan, N., Tüter, M. y Ayse Aksoy, H. (2003). Fatty acid compositions of flathead grey mullet (Mugil cephalus L., 1758) fillet, raw and beeswaxed caviar oils. Turkish Journal of Fisheries and Aquatic Sciences, 3, 93-96.

» Stoessel, L., Martínez, G. y Constenla, D. (2015). Análisis preliminar de ácidos grasos recuperados de cerámicas arqueológicas del curso del Río Colorado (Norpatagonia Central): Aportes para la subsistencia de grupos cazadores-recolectores. Magallania, 43(1), 231-249. http://dx.doi.org/10.4067/S0718-22442015000100013

» United States Testing Company, Inc. (1955). Tables and Data. New Jersey: Hoboken.

»Weitzel, C. y Flegenheimer, N. (2011). Artefactos fracturados y prácticas sociales en Cerro La China y Cerro El Sombrero. Trabajo presentado en el VI Congreso de Arqueología de la Región Pampeana Argentina, La Plata, Argentina.

»Zárate, M. (1986-1987). Marco estratigráfico y geológico del sitio 3 de la localidad arqueológica Cerro La China (Provincia de Buenos Aires). Relaciones de la Sociedad Argentina de Antropología, XVII(1), 29-35. http://www.saantropologia.com.ar/textos/marcoestratigrafico-y-geologico-del-sitio-3-cerro-la-china-provincia-de-buenos-aires/

»Zárate, M. (2005). El Cenozoico tardío continental de la provincia de Buenos Aires. Trabajo presentado en el Relatorio del XVI Congreso Geológico Argentino: Geología y Recursos Minerales de la Provincia de Buenos Aires, Buenos Aires, Argentina.

» Zárate, M. y Flegenheimer, N. (1991). Geoarchaeology of Cerro La China locality. Site 2 and Site 3. Geoarchaeology, 6, 273-94. https://doi.org/10.1002/gea.3340060304 